\title{
An overview of interactions between micronutrients and of micronutrients with drugs, genes and immune mechanisms
}

\author{
David I. Thurnham \\ Northern Ireland Centre for Food and Health, University of Ulster, Coleraine BT52 1SA, UK
}

\begin{abstract}
The objective of the present review is to examine critically the consequences of interactions that micronutrients undergo with nutrients and non-nutrients (mainly prescribed medicines) in diets and lifestyle factors (smoking, tea and alcohol consumption). In addition, the review describes recent work on interactions between nutrients and genes, the influence of gene polymorphisms on micronutrients, the impact of immune responses on micronutrients and specific interactions of antioxidant micronutrients in disease processes to minimise potential pro-oxidant damage.
\end{abstract}

Micronutrients: Medicinal drugs: Genes: Immune function: Antioxidants

Micronutrients are a diverse collection of substances required for intermediary metabolism in varying amounts but usually in amounts less than $1 \mathrm{~g} / \mathrm{d}$ and sometimes only a few $\mu \mathrm{g} / \mathrm{d}$. Most individuals obtain these substances from their food, but where malnutrition exists or the diet is monotonous and imbalanced, deficiencies can occur. Micronutrient deficiencies may be so severe as to cause clinical symptoms with major metabolic disturbances (Beaton et al. 1993; Underwood \& Arthur, 1996). Alternatively, an imbalanced diet may only produce a state of sub-optimal nutrition but this may also influence immune responses and the susceptibility to disease (Beaton et al. 1993). In such situations metabolic functions may be blunted (Munoz et al. 1995) and the body more vulnerable to toxins (Guengerich, 1995) or to physiological stresses; for example, resulting in complications of pregnancy (Keen et al. 2003). There is some evidence to suggest that a nutritionally sub-optimal situation may also exist in industrialised countries and is responsible for the high rates of CVD and some cancers (Diet and Health, 1989; World Health Organization, 1990; Beattie \& Kwun, 2004).

Poor diets are usually not just deficient in only one nutrient. The nutrient that is least adequate in the diet may cause the main clinical effects but if only that nutrient is replaced, other nutrients may then become critical, preventing any response to treatment. Nevertheless, at the community level, much work has already been done using single nutrient supplements with some striking successes as with vitamin A (Beaton et al. 1993) and Zn (Zinc Investigators Collaborative Group, 1999), although there have generally been much poorer outcomes with Fe (Underwood, 2003). Currently, health programmers are trying to develop strategies to give multi-nutrient supplements which contain the major nutrients likely to be low in the diet; commonly vitamin A, folate, Fe and Zn (Christian et al. 2003). The objective in giving any supplement is to produce a rapid improvement in nutritional status where dietary improvements may take many years and require complex interventions and close compliance by the recipients.

The potential for adverse consequences from both single- and multi-nutrient supplements through interaction with dietary components should not be overlooked. Supplements usually contain a disproportionately large amount of nutrient relative to normal dietary intakes, as the objective is to improve nutritional status rapidly. Giving large amounts of supplements can have surprisingly adverse effects. Nutrients may have toxic effects themselves on the body as in the case of vitamin A (Hathcock et al. 1990; Miller et al. 1998; Wiegand et al. 1998; Lips, $2003)$. Even non-toxic $\beta$-carotene $(\beta-C)$ increased mortality from lung cancer in smokers in two large intervention studies (Heinonen et al. 1994; Omenn et al. 1996). Nutrients can compete with one another and interfere with absorption as happens with Fe and Zn (Lynch, 1997; Sandstrom, 2001). Supplementary nutrients may exacerbate inflammation and thus worsen the effects of disease on the body (Wiegand et al. 1998). Fe is potentially a good example of this (Wiegand et al. 1998), but there are also reports that supplements of vitamin A can adversely affect respiratory disease (Stephensen et al. 2002a), and there is one

\footnotetext{
Abbreviations: APP, acute-phase protein; APR, acute-phase response; CYP, cytochrome P450; DHAA, dehydro-L-ascorbic acid; GPx, glutathione peroxidase; Hp, haptoglobin; IRP, Fe-regulatory proteins; LPS, lipopolysaccharide; MTHFR, 5,10-methylene-tetrahydrofolate reductase; NOS, NO synthase; PCT, proximal convoluted tubular; RBP, retinol-binding protein; ROI, reactive oxygen intermediates; RXR, retinoid X receptor; Th, T-helper; THF, tetrahydrofolate; VDR, vitamin D receptor; VDRE, vitamin D response element. 
report that vitamin A supplements increase the transmission of HIV to infants from the mother (Fawzi et al. 2003).

Physiologically, we adapt to handle nutrients and other substances at the concentrations in our diet and environment. We do have in-built safety mechanisms to handle large amounts of nutrients as well as the many thousands of xenobiotics in our diet. The biotransformation of some such compounds is handled by what are known as phase I and II reactions (Thomas, 1995; Alonso-Aperte \& VarelaMoreiras, 2000) (see later sections on interactions between nutritional status, lifestyle and xenobiotics; p. 217). Most endproducts of such biotransformations can be safely excreted by the host but there are some well-known exceptions. Intermediate compounds formed from dietary nitrosamines and aflatoxins are more toxic than the original and, in these cases, they are carcinogenic. The activity of phase I enzymes, however, can be both depressed as well as stimulated by substances in our diet and the actual activity of these enzymes may be a product of the habitual dietary environment in which we live (Guengerich, 1995). Hence individuals regularly consuming diets high in fruit and vegetables may metabolise potential carcinogens differently from others whose diet is low in these foods, and thereby have a lower risk of certain cancers. A well-balanced diet should contain adequate amounts of nutrients to maintain normal metabolism but also a wide range of non-nutrients to optimise phase I and II metabolic processes. The term 'non-nutrient' is used by the writer to indicate the many substances in our diet that have not been identified as being essential for life, but nevertheless can influence, or be influenced by, metabolic processes. Identifying the nature and amounts of relevant non-nutrients is outside the scope of the present review but readers wanting to know more about this fascinating area of nutrition should consult other reviews (Smith \& Yang, 1994; Yang et al. 1994).

It is proposed to examine a selection of the issues relating to micronutrient interactions. The first two sections will address drug-nutrient interactions and this includes lifestyle factors such as smoking and alcohol use. The next section will look at issues relating to the immune response and micronutrients. The fourth will address some issues relating to gene-nutrient interactions and the last section will address the question of inter-relationships between the antioxidant nutrients and their significance in maintaining health.

\section{Drug-nutrient interactions}

Drug-nutrient interactions can be categorised as physicochemical, physiological or pathophysiological (Roe, 1993) and particularly apply to older individuals in the community. Physicochemical interactions are represented by chelation causing the loss of a nutrient and lower activity of a drug. Physiological interactions include drug-induced changes in appetite, digestion, gastric emptying, biotransformation and renal excretion. Alterations in the metabolism, or tissue distribution, of vitamins A and D by female hormones producing higher plasma concentrations of retinol (Amatayakul et al. 1989; Ballew et al. 2001) and 25-hydroxycholecalciferol (Harris \& Dawson-Hughes, 1998) are also examples. Pathophysiological interactions occur when a drug impairs nutrient absorption or metabolism, or when drug toxicity causes an inhibition of metabolic processes. For example, symptoms of neurotoxicity can arise following the use of isoniazid, the toxicity of which is due to its chelating properties for pyridoxine, eventually depleting systemic pyridoxine concentrations (Lockman et al. 2001). Likewise, teratogenic effects of the anticonvulsant drug, valproic acid, may be due to an altered pattern of folate metabolites in the embryo (Wegner \& Nau, 1992) (Table 1).

Frequently, drug-nutrient interactions are bi-directional in their effects. For example, while the bioavailability of minerals is reduced by co-administration with some drugs, drug absorption is also reduced by nutrients, especially minerals, thereby reducing the effectiveness of the therapy (Polk et al. 1989; Campbell et al. 1992). Fe-drug interactions of clinical significance may involve a large number of therapies, for example those involving tetracycline derivatives, penicillamine, methyldopa, thyroxine, etc (Campbell \& Hasinoff, 1991). Furthermore, in addition to drugnutrient interactions influencing plasma nutrient concentrations, disease itself metabolically depresses the circulating concentrations of some nutrients and may increase requirements for nutrients (Thurnham, 1997a). Plasma concentrations of $\mathrm{Fe}$, retinol, ascorbate and $\mathrm{Zn}$ are rapidly and almost universally depressed by the inflammatory response and the physiological purpose in these changes should be understood in order to maximise benefits from supplementation (Thurnham \& Northrop-Clewes, 2003).

A drug-nutrient interaction refers to the effect of a medication on nutrients in the food we eat or those already in our bodies, or the converse, where food (Thomas, 1995) or dietary treatments (Campbell et al. 1992) may have an influence on the effectiveness of a drug. Food ingestion can profoundly affect a drug's pharmacodynamics and can either accelerate or retard drug absorption (Thomas, 1995). Where prolonged medication is prescribed, the potential interaction between food and drugs may be increased and this of course becomes of greater importance in older individuals. In older individuals, a depressed metabolism of drugs or a reduced urinary flow may increase the plasma concentration of a drug and maintain it for longer, so increasing the risk of interaction and toxicity (Bressler, 1993; Blumberg \& Couris, 1999). Risk factors which increase the potential for adverse outcomes of drugnutrient interactions are multiple medications, reduced nutrient intakes, nutrient loss from poor cooking habits, restrictive diets, anorexia, eating disorders, alcoholism, drug dependency or addiction, and renal and hepatic dysfunction (Thomas, 1995).

\section{Common drugs that influence handling or turnover of nutrients}

Medications may decrease appetite but usually the effects of drugs operate by altering nutrient absorption, metabolism or excretion (Table 1). The interactions described in this section are those where nutritional status is potentially impaired. However, nutrients may also interfere with drug absorption or metabolism and thereby reduce therapeutic effectiveness. 


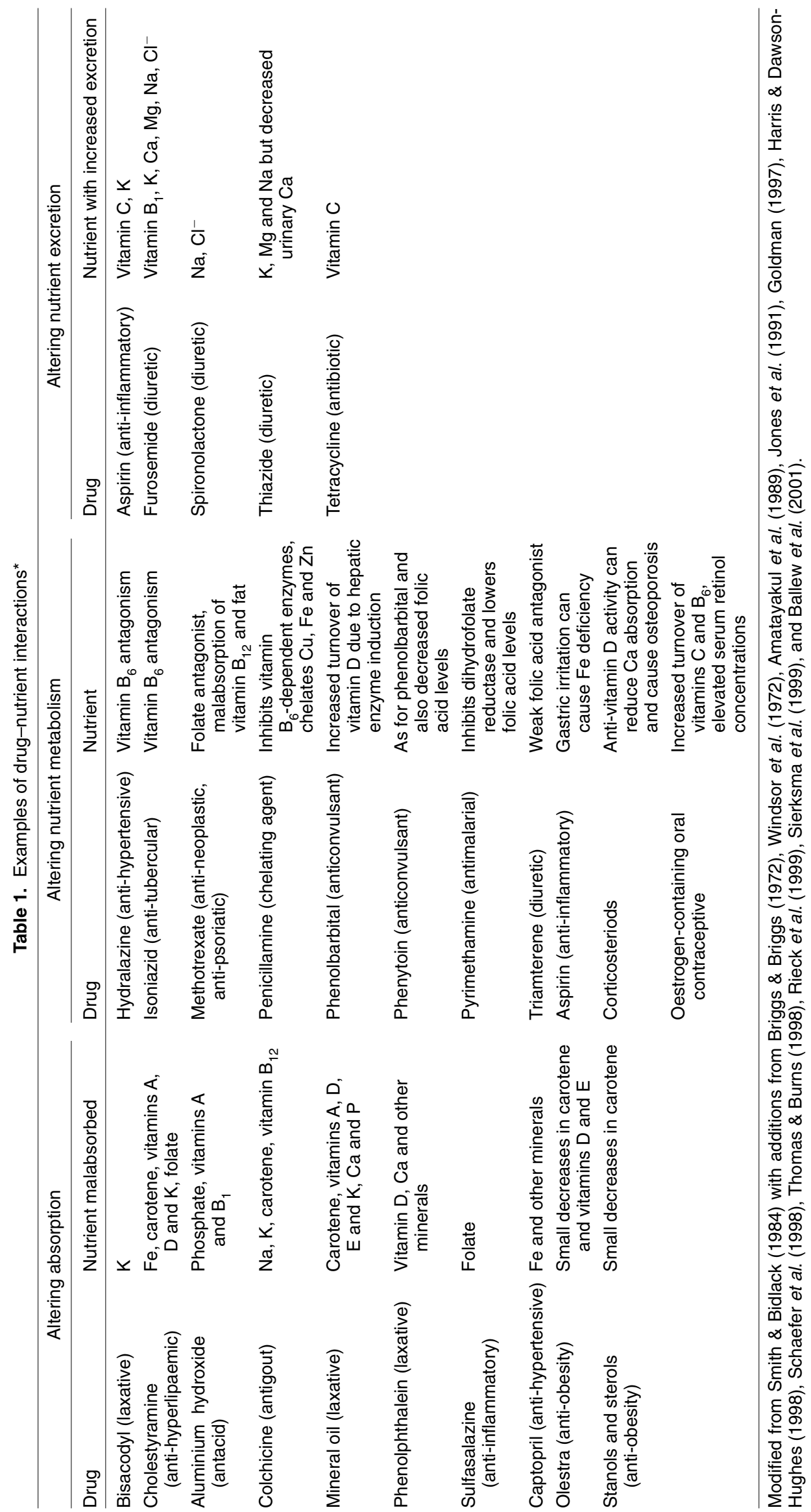


The short-term use of drugs is less likely to have adverse effects on nutritional status than long-term treatments. The problem is that the long-term use of many drugs is escalating. Over the last 40 years, the life expectancy of man has increased by almost 10 years in industrialised countries and by 20 years in parts of the developing world (Russell, 2000). As man lives longer the incidence of chronic diseases rises and the use of long-term drug therapy to fight the effects of chronic diseases such as arthritis, hypertension, coronary artery disease and adult-onset diabetes will continue to increase. Many classes of drugs, including antimicrobials, hypoglycaemics, and hypocholesterolaemic reagents, can be affected by the presence of food, with the geriatric patient being particularly at risk (Bressler, 1993; Thomas, 1995). In a recent survey in The Netherlands, $50 \%$ of individuals over the age of 65 years were using diuretics (van Kraaij et al. 1998). Some of the effects that commonly used medicines can have on micronutrients are described below.

Analgesic and anti-inflammatory. Aspirin is probably the best-known analgesic, and such drugs are intended to relieve pain. They commonly cause stomach irritation, and ingestion on an empty stomach is not advised (Thomas, 1995). Aspirin is also reported to lower plasma vitamin C concentrations but the mechanism is not known (Sahud \& Cohen, 1971; Alonso-Aperte \& Varela-Moreiras, 2000). Severe irritation to the stomach lining can cause bleeding leading to the loss of blood and the risk of anaemia through Fe deficiency (Hodkinson, 1985). In addition, it is suggested that aspirin alters the transport of folate by competition for binding sites on serum proteins, as $70 \%$ of patients with rheumatoid arthritis have low plasma folate concentrations (Alonso-Aperte \& Varela-Moreiras, 2000). Low folate concentrations potentially limit the availability of methyl groups derived from one-carbon metabolism. However, attempts to demonstrate the biological importance of low folate concentrations in response to long-term administration of aspirin or acetaminophen in earlier experimental studies found no evidence of any disturbance in DNA methylation or in several markers of the methionine cycle (Varela-Moreiras et al. 1993).

Antacids or acid blockers. Antacids neutralise stomach acid and acid blockers reduce the production of stomach acid. These drugs are the largest group of agents recognised to cause interactions along the gastrointestinal tract. Antacids may alter a substance's dissolution by modifying gastric $\mathrm{pH}$ and through chelation. $\mathrm{Al}$, a constituent of many antacids, can produce a relaxing effect on gastric smooth muscle that leads to a delay in gastric emptying time. Increased gastric $\mathrm{pH}$ leads to a reduced absorption of $\mathrm{Ca}$, $\mathrm{Fe}, \mathrm{Mg}$ and $\mathrm{Zn}$ (Thomas, 1995). Moderate gastric atrophy is common and autoimmune disease, leading to the loss of intrinsic factor in older individuals, can lead to vitamin $B_{12}$ malabsorption. Gastric acid and pepsin are needed to liberate protein-bound cobalamin from food and intrinsic factor is needed to bind cobalamin as part of the absorption process. Furthermore, Helicobacter pylori infection increases with age and has been implicated in both peptic ulcer disease and atrophic gastritis. Thus cobalamin malab- sorption may be exacerbated by anti-ulcer preparations which further lower gastric acidity. A study of outpatients in one hospital found 12-15\% of community-dwelling North American older individuals were $\mathrm{B}_{12}$ deficient (Pennypacker et al. 1991). And, in a retrospective study, the regular use of anti-ulcer drugs, especially histamine-2 blockers in the elderly, was found by Mitchell \& Rockwood (2001) to be significantly associated with the initiation of cobalamin therapy. While the latter is not proof that antiulcer preparations cause vitamin $B_{12}$ deficiency, it is suggestive that they might do.

Antibiotics. Antibiotics in general can decrease vitamin K synthesis by intestinal bacteria (Stieger et al. 1992) and impair clotting mechanisms. Antibiotics are used to treat bacterial infections and, when consumed by mouth, they will reduce the number and type of bacteria found in the intestine. Gut bacteria synthesise a family of compounds known as menaquinones $\left(\mathrm{Mk}\right.$; vitamin $\mathrm{K}_{2}$ ) that have side chains based on repeating 5C (prenyl) units (Mk-n). Man absorbs these in the lower intestine and the human liver normally stores about $90 \%$ vitamin $\mathrm{K}_{2}$ and the remaining $10 \%$ is phylloquinone (vitamin $\mathrm{K}_{1}$ ). Vitamin $\mathrm{K}_{1}$ is obtained mainly from green vegetables, and is the major form in the circulation. Vitamin $\mathrm{K}_{1}$ is also believed to be the more physiologically active form of vitamin $\mathrm{K}$ and therefore the impact of antibiotics on vitamin $\mathrm{K}_{2}$ synthesis and on clotting mechanisms is difficult to understand. However, antibiotics may affect vitamin $\mathrm{K}$ metabolism by other mechanisms; for example, the cephalosporin antibiotics can contribute to clinical hypoprothombinaemia by the inhibition of hepatic vitamin $\mathrm{K}$ epoxide reductase (Schafer et al. 1989). Tetracycline antibiotics bind to $\mathrm{Ca}$ found in dairy products, and the absorption of most tetracyclines is decreased by milk, antacids and by $\mathrm{Ca}, \mathrm{Fe}$ and $\mathrm{Mg}$ salts. Tetracyclines also bind to $\mathrm{Ca}$ in growing bones and teeth, causing staining. Although the interaction between the antibiotic and milk prevents both the absorption of some $\mathrm{Ca}$ and the antibiotic, the relative loss of $\mathrm{Ca}$ is probably small. Nevertheless in the elderly who are at risk of $\mathrm{Ca}$ deficiency and in whom osteoporosis is a common feature, additional $\mathrm{Ca}$ losses due to tetracycline therapy may be important. The elderly are also at risk from increasing gastric $\mathrm{pH}$ which retards the absorption of $\mathrm{Ca}$, and the increased use of loop diuretics facilitates the loss of $\mathrm{Ca}$ as well as other components in the urine (see later; p. 216) (Thomas \& Burns, 1998).

Anticoagulants. Drugs such as warfarin slow the process of blood clotting and this can decrease the risk of strokes in individuals whose blood shows tendencies to clot too easily. Such drugs function by interfering in the metabolism of vitamin $\mathrm{K}$ in blood clotting. Effective therapy is achieved by balancing the amount of anticoagulant against the usual intake of vitamin $\mathrm{K}$. Hence physicians warn against the consumption of foods high in vitamin $\mathrm{K}$ in case an elevated dietary intake of the vitamin impairs the effectiveness of the treatment (Smith \& Bidlack, 1984). In addition, haemorrhage caused by the anti-vitamin $\mathrm{K}$ action of antacids can be exaggerated in the elderly by taking antioxidants such as tocopherol (Thomas \& Burns, 1998) or very large doses of vitamin $\mathrm{C}$ ( $\geq 10 \mathrm{~g})$. However, even with these amounts of 
vitamin $\mathrm{C}$, there was no hypothrombinaemic action. Concurrent administration of vitamin $\mathrm{C}$ reduced plasma warfarin concentrations by about $17 \%$, probably due to diarrhoea attributable to the large intake of vitamin $\mathrm{C}$ (Feetam et al. 1975).

Anticonvulsants. Anticonvulsant drugs help control seizures. Phenytoin, phenobarbital and primidone can cause diarrhoea and decrease appetite, so reducing the availability of many nutrients. The drugs are particularly well known for their stimulatory effects on vitamin $\mathrm{D}$ turnover and catabolism by inducing the hepatic microsomal drugmetabolising system (Hahn et al. 1972). Vitamin D supplements may be needed to counter the drug effects.

Anticonvulsants also interact with the B vitamin, folate; blood folate concentrations fall shortly following the onset of therapy. Folate supplements will counter the adverse effects on folate status but they also adversely affect the efficiency of anticonvulsant treatment, so folate supplementation has to be monitored carefully. In man, the antiepileptic drug valproic acid is associated with teratogenicity and folate deficiency through unknown mechanisms, but possibly through effects on the methionine cycle (Alonso-Aperte \& Varela-Moreiras, 2000). Wegner \& Nau (1992) have demonstrated that valproic acid alters embryonic folate distribution in mice, producing ele- vated concentrations of tetrahydrofolate (THF) and lower concentrations of both formylated forms of folate. Such effects would seem to suggest that the vitamin $\mathrm{B}_{6}$-dependent enzyme responsible for the formation of 5,10-methylene-THF may be inhibited by valproic acid (see Fig. 1). Such alterations are partially prevented by the co-administration of folinic acid and $S$-adenosylmethionine, but nevertheless hypomethylation of DNA may be responsible for the teratogenesis (Alonso-Aperte \& Varela-Moreiras, 2000).

Anti-hyperlipaemic. Anti-hyperlipaemic drugs reduce blood cholesterol levels. Such drugs work by reducing fat absorption, a side effect of which is a reduction in absorption of the fat-soluble vitamins $\mathrm{A}, \mathrm{D}, \mathrm{E}$ and $\mathrm{K}$ and carotenoids. It is also reported that the absorption of vita$\min \mathrm{B}_{12}$, folate and $\mathrm{Ca}$ may also be affected.

Cholestyramine was one of the first of the cholesterolreducing drugs and is still used. Because such drugs cause malabsorption of fat-soluble nutrients, increased recommendations were made to raise the daily intake of vitamin A as long ago as 1985 (Roe, 1985) but cause-and-effect relationships between drugs and vitamin deficiency are difficult to prove, and the research has still not been done (Alonso-Aperte \& Varela-Moreiras, 2000).

More recently, the phytostanols were shown to have cho-
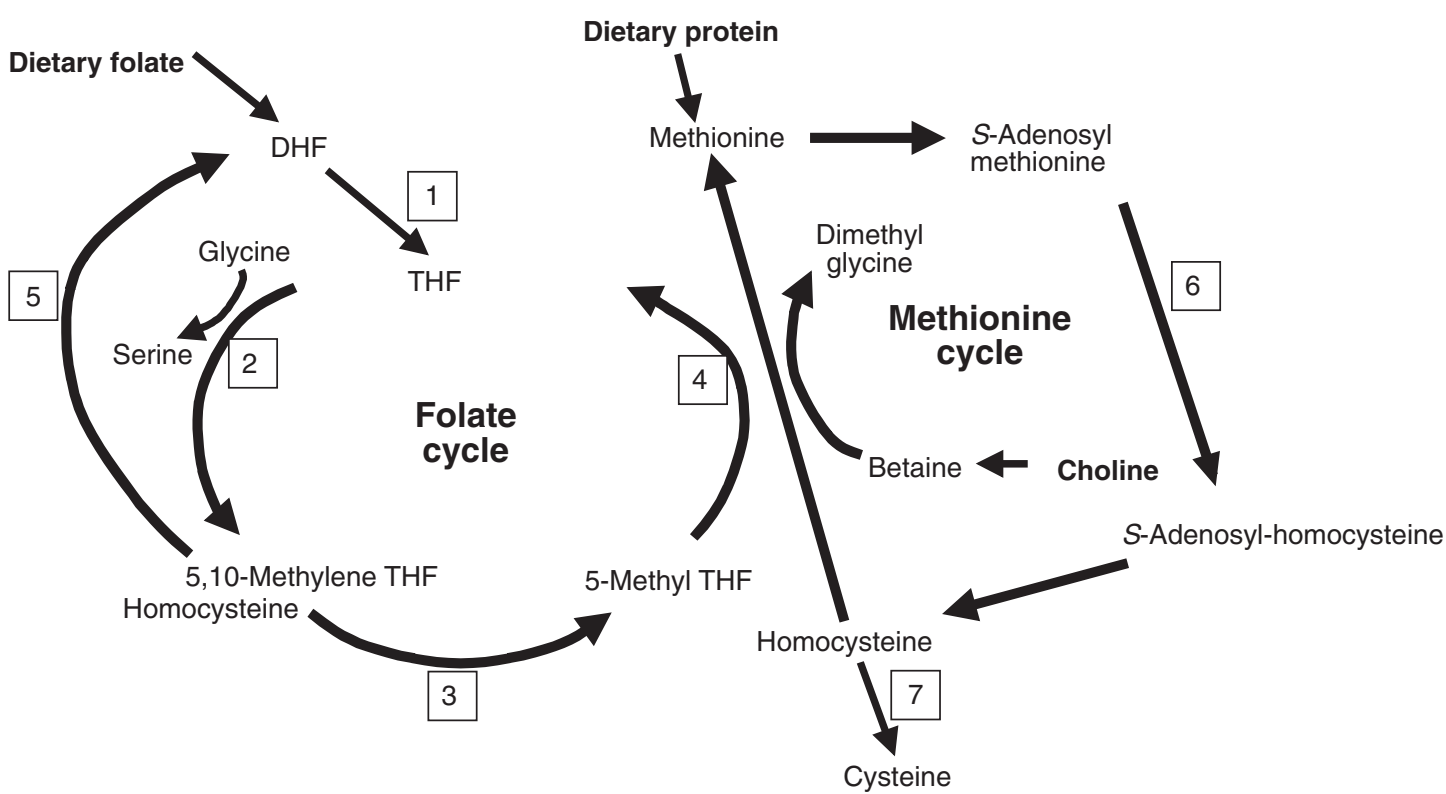

Fig. 1. Influence of vitamin status on folate and methionine cycles. Disturbances can arise from the following nutrient deficiencies: folate, cobalamin, riboflavin, pyridoxine and choline. In addition, drugs which inhibit dihydrofolate (DHF) reductase activity, such as methotrexate, have effects which are similar to folate deficiency. Deficiencies of folate, choline and the use of DHF reductase inhibitors (1) lower circulating metabolites of folate, impair the synthesis of $S$-adenosyl methionine and raise plasma homocysteine concentrations. Cobalamin (4) is needed for 5-methyl tetrahydrofolate (THF)-homocysteine methyl transferase activity. Cobalamin deficiency impairs folate interconversions, lowers THF and methionine and increases homocysteine concentrations. Riboflavin (3) is required for the enzyme 5,10-methylene THF reductase (MTHFR) which provides the methyl donor for methionine synthesis. The C677T polymorphism of the MTHFR gene appears particularly sensitive to riboflavin deficiency, lowering methionine and raising plasma homocysteine concentrations. Pyridoxine deficiency is rare in developed countries. Pyridoxal-5-phosphate (PLP) is required by many enzymes in protein metabolism. Deficiencies of PLP would probably affect folate metabolism by reducing the 5,10-methylene- and 5-methyl-THF metabolites (2) and so raising homocysteine concentrations and/or impairing the removal of homocysteine by inhibiting the transulfuration pathway (7). Pathways (5) and (6) enable purine and pyrimidine synthesis (5) and methyl group donation for lipid, protein and DNA metabolism (6). 
lesterol-lowering effects and have been incorporated into spreads for use in the home. Benecol and Flora-Pro-Active are the first products to be recognised as 'functional foods' on the UK market. Also in this category is 'Olestra'. Olestra is a compound formed by the esterification of sucrose and is a non-absorbable, tasteless, fat-like compound. Experience with all these compounds shows that while there are small variable decreases in plasma carotenoid concentrations following use of these substances, detectable effects on serum concentrations of vitamins A, D, E and K are minimal (Goldman, 1997; Hendriks et al. 1999).

Anti-hypertensive. Anti-hypertensive drugs are used to control blood pressure. They can affect body levels of $\mathrm{K}$, $\mathrm{Ca}$ and $\mathrm{Zn}$. Captopril, a hypotensive drug and an inhibitor of angiotensin-converting enzyme, can bind to $\mathrm{Fe}$ in the gut if jointly administered with Fe-containing mineral preparations. When $25 \mathrm{mg}$ captopril was administered orally with $300 \mathrm{mg}$ ferrous sulfate, there was a $37 \%$ reduction in the area under the curve of serum unconjugated captopril concentrations in normotensive human volunteers (Campbell \& Hasinoff, 1991; Schaefer et al. 1998). Food also interferes with the absorption of captopril, since food usually retards gastric emptying and elevates gastric $\mathrm{pH}$ (Mantyla et al. 1984). Bioavailability of the drug was reduced by more than $50 \%$; however the hypotensive effectiveness was no different apart from being delayed from about $1 \mathrm{~h}$ to $2 \mathrm{~h}$.

Anti-neoplastic. These agents are used to treat different forms of cancer. Frequently the drugs irritate the lining of the mouth, stomach and intestines and can damage mucosal cells, thus altering digestion. Many cause nausea, vomiting and/or diarrhoea. All of these effects can potentially influence nutrient status.

One particular drug in this group is methotrexate, which competitively inhibits dihydrofolate reductase and the production of THF for intracellular folate metabolism (Fig. 1). This limits the availability of methyl groups for single carbon transfer in the synthesis of purine and pyrimidines (Alonso-Aperte \& Varela-Moreiras, 2000). The biochemical perturbations caused by methotrexate are similar to those seen in choline deficiency. Animals on low-dose methotrexate have diminished hepatic folate levels, $S$-adenosylmethionine, methionine and betaine. The action of methotrexate on dihydrofolate reductase inhibits the reduction of pteroyl glutamate (folic acid) to tetrahydropteroyl glutamate (THF) and as a consequence both the supplies of folate co-enzymes and of the tetrahydropteroyl glutamate substrate for the conversion to polyglutamate derivatives (and liver storage) are impaired. Methotrexate also inhibits the transport across the intestine and into hepatocytes and there was a $48 \%$ reduction in hepatic folate content as a result of the methotrexate treatment. The consequence of methotrexate treatment on the distribution of folate metabolites was a decrease in 5-methyl-THF and an increase in formyl-THF. There was no change in the relative concentration of THF. The sharp decline in the concentration of 5-methyl-THF concentrations associated with methotrexate treatment would impede the conversion of homocysteine to methionine. Plasma homocysteine concen- trations were not measured but methionine was reduced (Selhub et al. 1991).

Therapeutic efficiency and adverse effects of methotrexate therapy on folate metabolism will depend on the relative amounts of methotrexate and folic acid in the diet. To reduce the adverse side effects of methotrexate on folate metabolism, folic acid has been given together with the drug. As this potentially decreases the effectiveness of the therapy, the situation has to be monitored carefully. For a further discussion on folate metabolism and micronutrient interactions, see the section on vitamin status and homocysteine concentrations (p. 228).

Anti-tubercular. The anti-tubercular drug isoniazid (isonicotinic acid hydrazide) binds to pyridoxal phosphate and increases the risk of vitamin $\mathrm{B}_{6}$ deficiency during treatment. In recent years there has been an increase in tuberculosis and with it a corresponding increase in isoniazid-induced neurotoxicity (Temmerman et al. 1999). Acute toxic effects of isoniazid can also be precipitated by an overdose of as little as $1.5 \mathrm{~g}$ and doses larger than $30 \mathrm{mg} / \mathrm{kg}$ often produce seizures (Romero \& Kuczler, 1998). Pyridoxal phosphate is a necessary cofactor for the production of the neurotransmitter $\gamma$-aminobutyric acid. If isoniazid combines with pyridoxal phosphate it can lead to a reduction in levels of $\gamma$-aminobutyric in the brain (Wood $\&$ Peesker, 1972). Along with treatment to reduce the seizures, pyridoxine should be administered in a dose equivalent to the suspected amount of drug ingested (Romero \& Kuczler, 1998).

Isoniazid can also inhibit hepatic vitamin D 25-hydroxylation and possibly affect metabolism of the vitamin (Bengoa et al. 1984). In addition, pellagra is a recognised complication of isoniazid therapy (Darvay et al. 1999). Pellagra is the deficiency disease associated with a deficiency of the vitamin niacin (nicotinic acid). There are two main sources of niacin in the diet, niacin and the amino acid tryptophan. The body can convert tryptophan to nicotinic acid through a series of steps, several of which require pyridoxal phosphate as co-enzyme. Hence isoniazid therapy can result in pellagra.

Diuretics. Diuretics stimulate the increased excretion of urine and with it the risk of increased losses of $\mathrm{K}, \mathrm{Mg}$ and $\mathrm{Ca}$ and the water-soluble vitamins. Thiamin status in the elderly is of particular concern in relation to the use of diuretics. Total body thiamin content is rather small and thiamin has a high turnover rate, with a half-life of 10-18 d. Thus to maintain optimal thiamin status, a constant supply of dietary thiamin must be assured (Suter \& Vetter, 2000). One particular diuretic, furosemide, has been associated with thiamin deficiency in elderly patients (Pepersack et al. 1999). Work has shown, however, that all diuretics lead to increased losses of urinary thiamin (Lubetsky et al. 1999; Rieck et al. 1999) but furosemide has also been shown to impair the uptake of thiamin by cardiac cells in vitro (Zangen et al. 1998). However, the clinical importance of the latter effect still needs to be confirmed.

Laxatives. Laxatives speed up the movement of material through the digestive tract, so potentially reducing the time 
for nutrient absorption. So, the excessive use of laxatives may deplete vitamins, especially the fat-soluble vitamins A, $\mathrm{D}, \mathrm{E}$ and $\mathrm{K}$ and minerals such as $\mathrm{Na}$ and $\mathrm{K}$ needed for normal body functions. There may also be increased fluid losses leading to dehydration. Usually electrolytes are reabsorbed in the large intestine; however, laxatives may not allow adequate time for this to occur (Blumberg \& Couris, 1999).

Drugs and tropical diseases. Vector-borne diseases (malaria, sleeping sickness, arbovirus diseases, blood flukes), viral diseases (haemorrhagic fevers), AIDS and illnesses due to malnutrition affect vast areas of the tropics, and there is undoubtedly considerable interaction between the diseases and between the diseases and malnutrition. Such interactions, however, are generally not the subject of the present review. As with many of the drugs used in Western medicine, there are the general effects of food affecting drug efficiency. Thus for the anti-helmintic drug, albendazole, experiments in sheep have shown it is pharmacokinetically $50 \%$ more effective if fed to starved as opposed to fed animals (Lifschitz et al. 1997). Likewise, Lumifantrine, one of the antimalarial drugs used when multi-drug resistance is a complication, is almost insoluble in water and administering it with food if possible improves its absorption and effectiveness. Patients receiving the antimalarial drug Fansidar should be adequately hydrated, as the long in vivo half-lives of the components increase the risk of crystaluria (Pharmaceutical Information, 2004). However, there appear to be very few reports of specific interactions between drugs used to combat tropical diseases and specific nutrients, but this may be due to the widespread malnutrition and low socio-economic conditions present in many developing countries. Thus, apart from general information on desirable conditions for the administration of drugs used in tropical medicine, there is little specific information on drug-nutrient interactions except for some antimalarial drugs.

Several antimalarial drugs interfere with folate metabolism. The malaria parasite requires $p$-aminobenzoic acid and drugs such as sulfonamides interfere with its ability to obtain this essential nutrient and with the biosynthesis of tetrahydrofolic acid. For example, Fansidar contains sulfadoxine, a structural analogue of $p$-aminobenzoic acid and pyrimethamine, a competitive inhibitor of the enzyme dihyrofolate reductase. The combined use of Fansidar with other drugs having antifolate activity may produce megaloblastic anaemia and such drugs should not be used in patients with megaloblastic anaemia due to folate deficiency.

Two other specific drug-nutrient interactions have been reported in connection with antimalarial drugs. Quinine is reported to potentiate the anticoagulant action of warfarin (Stenton et al. 2001), and it is also suggested that the sulfonamide in Fansidar may displace orally administered anticoagulants from their carrier proteins, increasing their anti-coagulant effects (Pharmaceutical Information, 2004). Last, in vitro studies with supplements of the B vitamin, riboflavin, report potentiation of the activities of several antimalarial drugs (mefloquine, pyrimethamine and quinine) against the asexual parasite forms of Plasmodium fal- ciparum (Akompong et al. 2000a). The authors suggest that the reducing properties of riboflavin interfere with the oxidation of $\mathrm{Hb}$ in the food vacuole of the parasite, since levels of oxidised $\mathrm{Hb}$, the accumulation of haemozoin (oxidised and polymerised $\mathrm{Hb}$ ) and the size of the food vacuole in riboflavin-treated parasites were all reduced by approximately $50 \%$ (Akompong et al. 2000b).

\section{Influence of nutrients or nutritional status on drug metabolism}

The processing or detoxification of drugs and the many foreign compounds that enter our bodies daily in food is done by processes that have been collectively termed phase I and phase II enzyme-catalysed reactions. Phase I reactions include oxidation, hydroxylation, reduction and hydrolysis, leading to changes in the functional groups on molecules. Phase I activity occurs predominantly in the liver and comprises the microsomal or mixed function oxidase systems, NADPH-dependent enzymes and cytochromes $\mathrm{P} 450$, the latter in liver, lung and small intestine. The second phase of the transformation is of a synthetic nature and involves conjugation with glucuronate, sulfate or glycine to enable excretion of the conjugate in the urine or bile. In general the intermediate compounds formed by these reactions are safe but there are exceptions, for example, most nitrosoamines, where the products of the phase I reaction are potential carcinogens (Guengerich, 1995).

Cytochrome P450 (CYP) proteins in man are drugmetabolising enzymes but some are also necessary for metabolising important endogenous compounds, for example, cholesterol, prostacyclins, thromoboxane A2, bile acids, steroids, and the degradation of vitamins $\mathrm{A}$ and $\mathrm{D}$, etc. The P450 proteins are membrane-bound, haem-containing enzymes found in the endoplasmic reticulum and some are found in the mitochondrial inner membrane. There are two different electron transport chains for the P450 cytochromes depending upon location, but both involve NADPH and flavin co-enzymes. The P450 proteins are categorised into families and subfamilies by similarities in their amino acid structure. Sequences that are more than $40 \%$ identical belong to the same family and those more than $50 \%$ identical, to the same subfamily. In man there are eighteen families and forty-three subfamilies of the CYP genes (Nelson, 2003). Most drugs and other foreign compounds in our diet are metabolised by cytochromes from three families; CYP1, CYP2 and CYP3. Compounds may induce or inhibit specific CYP enzymes and interactions between two or more compounds and the cytochromes are common. The CYP3A subfamily is one of the most important drug-metabolising and abundant P450 proteins in the human liver. It is known to metabolise 120 different drugs, for example, acetaminophen (anti-inflammatory), codeine (analgesic), cyclosporin A (immuno-suppressant), diazepam (anti-depressant), warfarin (anti-coagulant), etc.

Many nutrients and micronutrients can potentially affect phase I enzyme activity, for example niacin and riboflavin are needed for mitochondrial electron transport, $\mathrm{Fe}$ and glycine are needed for haem synthesis for CYP, and miner- 
als such as $\mathrm{Ca}, \mathrm{Zn}$ and $\mathrm{Mg}$ are needed to maintain membrane integrity. Ca regulation within the cell plays an important role in cell homeostasis (Hoyumpa \& Schenker, 1982). Normal intracellular Ca concentration in the cytosol is less than $0 \cdot 1 \mu \mathrm{M}$ but is $1.3 \mathrm{~mm}$ outside the cell or in the mitochondria or endoplasmic reticulum. The gradients are maintained by ATPase pumps which require normal mitochondrial activity for cellular respiration. $\mathrm{Mg}$ is needed for mitochondrial membrane stability and, together with thiamin diphosphate, is an essential co-enzyme for pyruvate decarboxylase which provides the essential substrate, acetyl-CoA, for mitochondrial function. Last, high Zn concentrations $(2-10 \mu \mathrm{M})$ can induce an increase in inner mitochondrial membrane permeability by opening a high-conductance channel (Wudarczyk et al. 1999). Its effects may be caused by interactions with proteins by binding to various mitochondrial sulfhydryl groups and inhibiting the mitochondrial electron transport chain. The effects of $\mathrm{Zn}$ are inhibited by $\mathrm{Mg}$ at physiological concentrations (Wudarczyk et al. 1999). However, cytosolic concentrations of $\mathrm{Zn}$ are three times higher than those in mitochondria and it has recently been reported that the transport of $\mathrm{Zn}$ across lipid bilayers is substantially increased by lipid peroxidation and that an excessive influx of $\mathrm{Zn}$ might be associated with cell death (Pattison et al. 2004). In addition, it has recently been suggested that fluctuations in plasma $\mathrm{Zn}$ can have a rapid influence on cell metabolism, especially of endothelial cells. Zn-depleted cells become more sensitive to signalling molecules and much more susceptible to oxidant stress (Beattie \& Kwun, 2004). It is difficult to establish to what extent low nutritional status influences mixed-function oxidase systems activity in vivo but considerable experimental work suggests that the CYP system seems to be sensitive to a number of vitamin deficiencies, including vitamins A, B group, C and E (Guengerich, 1995).

In the case of vitamin C it was reported as early as 1941 that the pentobarbital sleeping time was prolonged in scorbutic guinea-pigs. Zannoni and colleagues showed that the activity of CYP and NADPH cytochrome P450 reductase decreased significantly when microsomal ascorbate had dropped to $30 \%$ of normal. Enzyme activity took about $6 \mathrm{~d}$ to return to normal on repletion with ascorbate and most of the effects of vitamin $\mathrm{C}$ deficiency occurred in younger animals (200-250 g) (Zannoni \& Lynch, 1973). However, there is uncertainty whether human CYP enzymes are also sensitive to vitamin $\mathrm{C}$ deficiency, since an attempt to exploit the sensitivity and assess vitamin $\mathrm{C}$ status in man by his ability to metabolise ${ }^{13} \mathrm{C}$-labelled methacetin did not appear to work. This was in spite of the fact that when guinea-pigs in various stages of vitamin $\mathrm{C}$ depletion were given $\left[{ }^{14} \mathrm{C}\right]$ methacetin and breath ${ }^{14} \mathrm{CO}_{2}$ was collected, the amount of label found in the breath was there in proportion to status. However, a human study carried out in adult Gambian males failed to demonstrate any correlation between the metabolism of $\left[{ }^{13} \mathrm{C}\right]$ methacetin and vitamin $\mathrm{C}$ status (Powers, 1987, 1991). The reasons for the failure of the human study may be because the vitamin $\mathrm{C}$ deficiency in the guinea-pigs was more severe. Alternatively, the guinea-pigs were young growing animals and it may be that it is only in growing infants and children that the P450 enzymes are sensitive to inadequate vitamin $\mathrm{C}$ status. It is also becoming clearer that there are considerable interspecies differences in P450 metabolism of xenobiotics (Nelson, 1999), which might explain the different behaviour between man and guinea-pigs.

\section{Malnutrition, P450 enzymes and cancer}

In contrast to vitamin $\mathrm{C}$, however, deficiencies of energy (protein and carbohydrate) reduce P450 enzyme-catalysed oxidations in man. For example, children with kwashiorkor have lower rates of drug metabolism (Guengerich, 1995). There are also many other examples of foods and nutrients influencing human P450 enzyme activity, such as the striking effects of flavonoids. Following a single glass of grapefruit juice, which contained a flavonoid that inhibits a P450 CYP3A4 subfamily enzyme, peak plasma concentrations and areas under the curve of several $\mathrm{Ca}$ channel-blocking drugs used to treat essential hypertension were elevated four- to five-fold (Guengerich et al. 1986). More recently others have shown that the potency of many more drugs is increased by grapefruit juice, for example drugs to reduce angina, convulsions, blood pressure, etc (Dresser et al. 2000; Kane \& Lipsky, 2000). Other dietary substances with potentially protective effects against carcinogenic compounds are the $\mathrm{S}$ compounds in onions and garlic, the isothiocyanates and indoles in cruciferous plants, capsaicin in capsicum fruits, etc. Experimental work with many of these substances that inhibit phase I or II enzymes show that they block tumour formation, and there is growing evidence of their effectiveness in man. The role of dietary inadequacies and excesses in influencing P450 activity in man may also be of fundamental importance in obtaining a better understanding of the aetiology of several diet-linked cancers. For example, alcohol consumption is associated with head and neck cancers, smoking with lung cancers and a diet high in salt is associated with gastric cancers, etc. In contrast, diets high in fruit and vegetables are associated with a general protection against many cancers and, as indicated earlier (p. 212), several classes of compound are now known to inhibit or induce different P450 enzymes known to metabolise compounds to carcinogenic intermediates. Anyone interested in exploring the potential ramifications and interactions of diet (deficiency and excess), drugs of abuse and the different P450 enzymes which may play a part in the aetiology of these cancers should consult the reviews by Smith \& Yang (1994), Yang et al. (1994), Guengerich (1995), and Nelson (1999, 2003).

\section{Lifestyle habits and nutrient status}

Tea consumption and nutrient status. Polyphenol-containing beverages, such as tea, reduce non-haem-Fe bioavailability (Disler et al. 1975; Brune et al. 1989); hence several workers have investigated the possibility that tea consumption might interfere with $\mathrm{Fe}$ absorption and cause anaemia. Temme \& van Hoydonck (2002) examined all studies where tea consumption and Fe status had been examined up to June 2001. Sixteen studies were evaluated and these included all sections of society. All studies were done in Western populations except one in China and another in 
Zaire (now Democratic Republic of Congo). The overview concluded that tea consumption does not influence Fe status in Western populations where most individuals have adequate Fe stores. Where individuals had marginal Fe status, a negative association of ferritin or $\mathrm{Hb}$ with tea consumption occurred but associations were generally weak, except for in one study where the number of subjects studied was small (Temme \& van Hoydonck, 2002). Recent experimental work suggests that flesh foods (beef, poultry and seafood), phytic acid and vitamin $\mathrm{C}$ are probably the most important factors determining Fe bioavailability (Reddy et al. 2000).

Smoking and nutrient status. Smokers have a higher risk of lung and other cancers than non-smokers. The exact cause of smoking-related cancers is not known but tobacco smoke contains large amounts of reactive species which may well be implicated in tissue damage and the initiation of cancer cell development. In addition, smoking can adversely influence the metabolism of some known dietary carcinogens and thus smokers may have higher risks of cancer from dietary or other environmental factors than non-smokers. CYP2A6 is the principal liver enzyme involved in nicotine clearance and it is also involved in the activation of several hepatotoxins, notably nitrosamines and aflatoxin $\mathrm{B}_{1}$ (Pelkonen et al. 2000). It has been shown that some tobacco-specific nitrosamines have a high affinity for this enzyme (Raunio et al. 2001). Heavy smokers are likely to have higher CYP2A6 enzyme activity although there are inter-individual variations in CYP2A6 levels that affect nicotine inactivation rates as well as also potentially influencing smoking patterns. There is a relatively high rate of the CYP2A6 gene deletion in Asian populations resulting in a generally reduced activity in these populations and possibly reduced risks of lung cancer (Raunio et al. 2001). The CYP2A6 enzyme is also induced by anticonvulsant drugs but is not altered by acute alcohol ingestion (Pelkonen et al. 2000).

Two large studies reported an increased risk of lung cancer in individuals receiving $20-30 \mathrm{mg} \beta$-carotene $(\beta-\mathrm{C}) / \mathrm{d}$ for 4 or more years (Table 2). Activation of cytochrome enzymes may lie at the centre of the explanation as to why $\beta-C$ supplements increase the risk of lung cancer in smokers. Paolini et al. (1999) reported significant increases in the carcinogen-activating enzymes (CYP1A1/2, CYP3, CYP2B1, CYP2A) in the lungs of rats supplemented with high doses of $\beta-C$. In man, correspondingly high enzyme activities of these CYP would predispose tobacco-smokeexposed individuals to an increased cancer risk from bioactivated tobacco-smoke pro-carcinogens. Furthermore, in the two supplementation studies where there was no increased cancer risk (Physicians' Study, $50 \mathrm{mg} \beta-\mathrm{C}$ every other day; Hennekens et al. 1996) or a reduced risk (China study, 15 $\mathrm{mg} \beta-\mathrm{C} / \mathrm{d}$; Blot et al. 1993), the results do not conflict with the suggestions of Paolini et al. (1999). In the Physicians' Study, the majority of the participants were not smokers; therefore exposure to bioactivated, smoke-related pro-carcinogens would have been minimal. In the China Study, most men would have smoked clay pipes and women would have been non-smokers (Thurnham et al. 1988). Exposure to pro-carcinogens may have been minimised by the method of smoking and any gene deletion of CYP2A6, such as that reported in Japanese populations (Raunio et al. 2001), would also have reduced risk. Thus the adverse effects of $\beta-C$ supplements may have been due to the induction of phase I 'carcinogen-activating' enzymes in individuals already exposed to elevated levels of pro-carcinogens.

Smoking is associated with the lower dietary intake of many foods, including fruit and vegetables and dairy products (Rock et al. 1999; Morabia et al. 2000). In addition, smokers frequently have lower plasma concentrations of nutrients than non-smokers even when dietary intake is taken into account, for example with vitamin C (Faruque et al. 1995) and most carotenoids (Thurnham, 1990a). In fact others have shown that smoking a single cigarette over a period of $10 \mathrm{~min}$ reduced the concentration of plasma nitrate and nitrite (by about $13 \%$ ) and of vitamin C (by about $23 \%$ ) at $5 \mathrm{~min}$, though in all cases concentrations returned to normal at $60 \mathrm{~min}$ (Tsuchiya et al. 2002).

There is an increased risk of bone demineralisation, fractures and osteoporosis in women who smoke (Law \& Hackshaw, 1997) and a population-based survey of 2319 Swiss women using a validated food-frequency questionnaire reported that smokers consumed significantly less $\mathrm{Ca}$ and vitamin $\mathrm{D}$ than non-smokers, never-smokers or exsmokers (Morabia et al. 2000). Dietary vitamin D is usually a poor predictor of vitamin D status, as sunlight provides our main supply. Nevertheless, others have also found plasma 25-hydroxycholecalciferol concentrations to be significantly lower in heavy smokers than in non-smokers and this was accompanied by lower $\mathrm{Ca}$ absorption, but there was no difference in bone density at any site in the two groups of elderly women studied (Rapuri et al. 2000). Whether the P450 enzyme CYP24, which is responsible for vitamin D degradation (Nelson, 2003), is induced by smoking has not to the writer's knowledge been investigated.

In a recent review of the evidence for the effects of smoking and alcohol use on micronutrient requirements in pregnancy, it was suggested that vitamin $C$ requirements increase for pregnant smokers and that plasma concentrations of $\beta-C$, vitamin $B_{12}$, vitamin $B_{6}$ and folate concentrations are lower in pregnant than non-pregnant smokers. The authors were unclear, however, whether the lower concentrations were due to increased requirements, lower dietary or supplement intakes, haemodilution or other factors (Cogswell et al. 2003). The authors also reported that $\mathrm{Fe}$ supplementation partially ameliorates impaired fetal growth caused by $\mathrm{Cd}$ intake from cigarette smoke in experimental studies.

Ethyl alcohol consumption and nutritional status. The consumption of ethyl alcohol impairs the absorption of thiamin in both man and the rat (Thomson et al. 1970; Hoyumpa et al. 1977; Ibner et al. 1982). Ethyl alcohol inhibits the active but not the passive process of thiamin absorption. Note, this is different from the mechanism of action of thiaminases in raw fish, bracken and tea, where potentially all dietary thiamin is vulnerable to degradation (Cathcart \& Thurnham, 1998). The active process of thiamin absorption occurs as a result of the ATPase found in the brush-border membrane in the jejunum in the rat. Ethanol at $0.5 \mathrm{M}$, added in vitro to brush-border membrane 


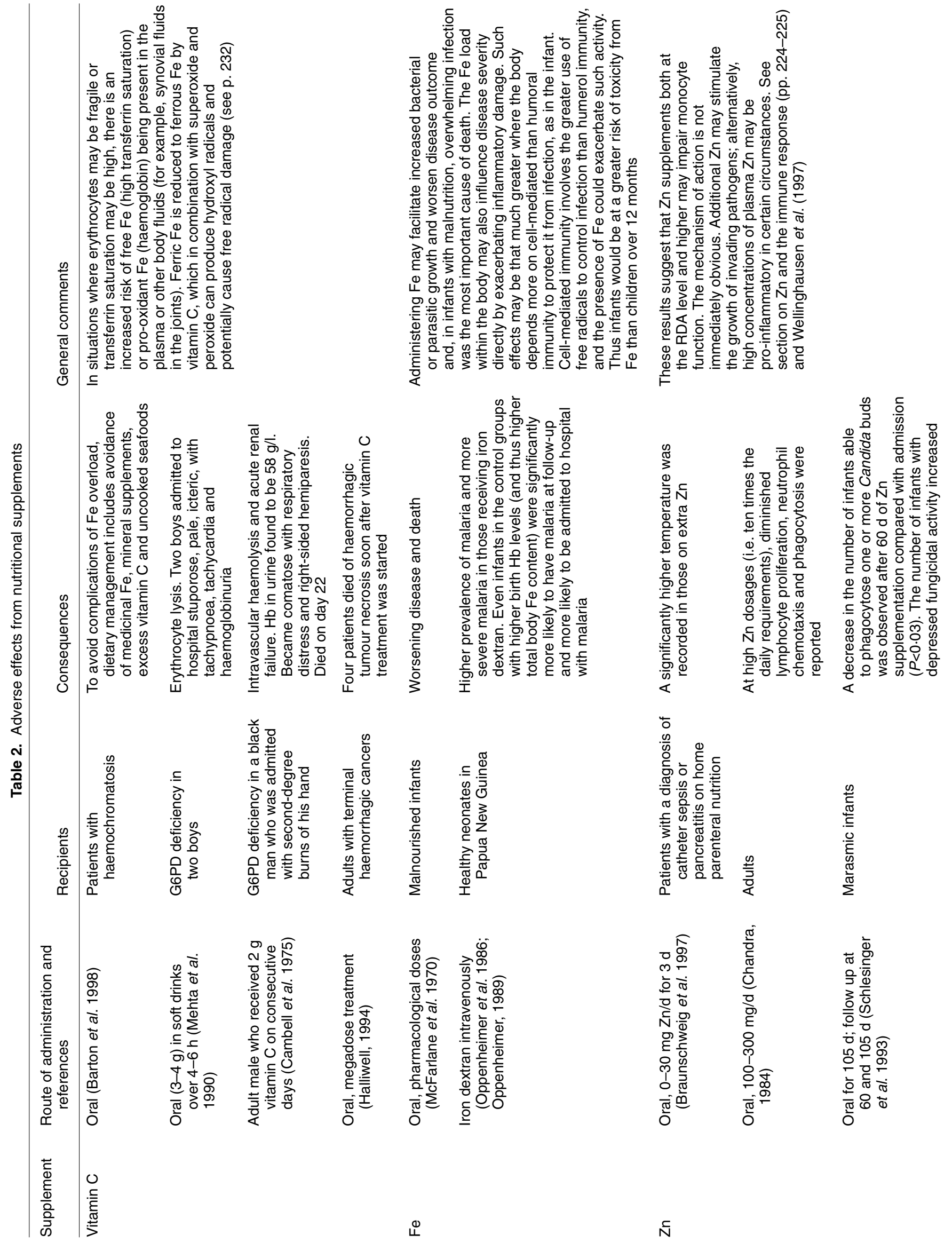



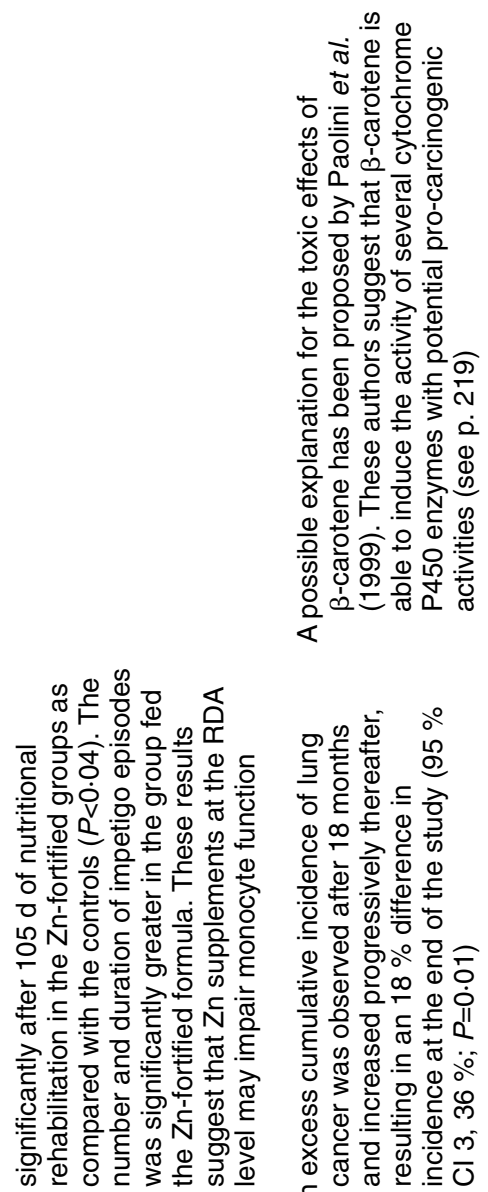
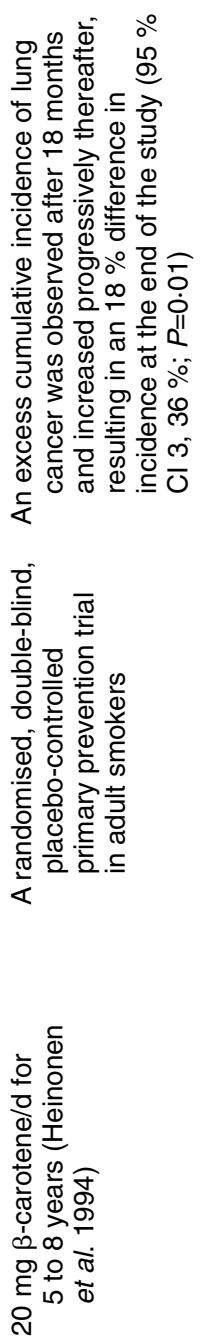

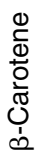

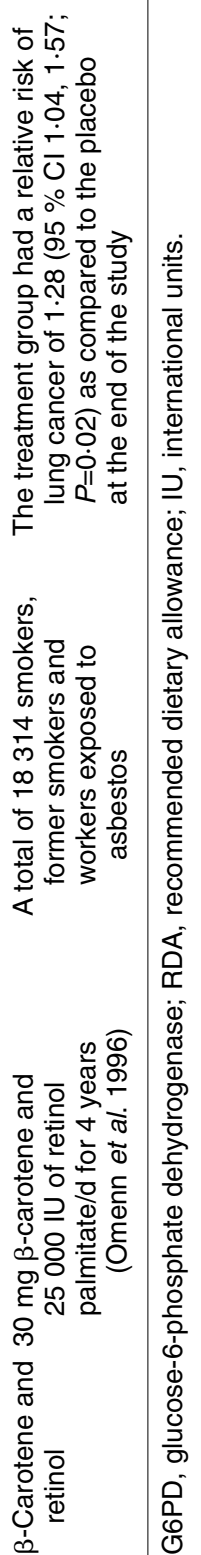

reduced ATPase activity in the jejunum by $41 \%$ (Hoyumpa et al. 1977). At low dietary thiamin concentrations $(<1 \cdot 0$ $\mu \mathrm{mol} / \mathrm{l})$, transport is a saturable, Na-dependent active process that proceeds against an electrochemical gradient and is adversely affected by anoxia, low temperature, metabolic inhibitors and structural analogues. At concentrations above $1.0 \mu \mathrm{mol} / 1$, thiamin transport is unaffected by these factors and appears to be a passive process.

Likewise, in human subjects, parenteral alcohol administration reduces the absorption of thiamin. ${ }^{35}$ S-labelled thiamin was given to twelve healthy subjects and thirteen patients with fatty liver and a history of chronic alcoholism (Thomson et al. 1970). Subjects were given $200 \mathrm{mg}$ thiamin to saturate deposits before the experiment. Labelled thiamin was absorbed via the portal venous system. A mean increase in blood thiamin of $15 \mu \mathrm{g} / \mathrm{l}$ occurred in the healthy subjects $90 \mathrm{~min}$ after $5 \mathrm{mg}$ thiamin $\mathrm{HCl}$ and about $35 \%$ of the labelled thiamin was recovered from urine over a $72 \mathrm{~h}$ period. Oral ethanol $(1 \cdot 5-2 \mathrm{~g} / \mathrm{kg})$ caused a $40 \%$ or more reduction in blood and urine thiamin concentrations in 25 $\%$ of the normal subjects while a mean decrease of $60 \%$ of blood and urine thiamin concentrations occurred in the alcoholics. Reduced absorptive capacity for thiamin persists despite the receipt of thiamin and other vitamins for 3-4 $\mathrm{d}$ but the effects of the alcohol were reversible since thiamin absorption, general nutriture and hepatic morphology had returned to normal after a 2-3-month period of adequate nutrition and abstinence from alcohol (Thomson et al. 1970).

In addition, animal studies suggest that chronic alcohol consumption at levels of $20-50 \%$ of energy intake during pregnancy may mobilise fetal vitamin A from the liver and result in increases in vitamin A in fetal organs and subsequent defects (Cogswell et al. 2003). A deterioration in the mother's vitamin A stores may also jeopardise the amount of vitamin A in her milk. This could possibly influence the vitamin A status of the breast-fed infant since the human infant is born with very little hepatic vitamin A; it depends on its mother's milk in the early months of life for vitamin A. Chronic alcohol abuse is known to interfere with the storage of liver vitamin A in adults (Leo \& Lieber, 1982), and poor control of plasma retinol concentrations could have adverse consequences for the fetus at an earlier stage of development, as excess vitamin A is known to have teratogenic effects.

Alcohol abuse results in a striking depletion of hepatic vitamin A (Leo \& Lieber, 1982). Ethanol is oxidised to acetaldehyde by two enzyme systems; alcohol dehydrogenase and the microsomal ethanol oxidising system. The predominant enzyme in the latter system is CYP2E1 (McCarver, 2001). Isozymes of alcohol and other dehydrogenases convert ethanol and retinol to their corresponding aldehydes in vitro. In addition, new pathways of retinol metabolism have been described in hepatic microsomes that involve, in part, CYP enzymes, which can metabolise various drugs. In view of these overlapping metabolic pathways, it is not surprising that multiple interactions between retinol, ethanol and other drugs occur. Accordingly, the prolonged use of alcohol, drugs, or both, results not only in a decreased dietary intake of retinoids and carotenoids, but also accelerates the breakdown of retinol through cross- 
induction of degradative enzymes. In addition, acetaldehyde interacts with liver stellate cells, the main storage sites of retinol in the body, stimulating their capacity to produce fibrous tissue and impairing the ability to store retinol (Leo \& Lieber, 1999).

\section{Micronutrients and the immune response}

The immune response is part of an orchestrated series of responses by the body known as the acute-phase response (APR) that follows infection or trauma. The APR is essentially a protective response of the body against the danger posed by disease and is designed to facilitate both the inflammatory and repair processes, and to protect the organism against the potentially destructive action of inflammatory products (Steel \& Whitehead, 1994). For example, tissue damage can be controlled or reduced by limiting cytokine production, neutralising reactive oxygen intermediates, inhibiting proteinases, etc (Tilg et al. 1997). Reductions occur in the concentration of several plasma nutrients with the onset of the immune response and these may be misinterpreted as nutrient deficiencies (Thurnham, 1997a). These falls in circulating nutrient concentrations can occur very rapidly and initially they are probably a consequence of increased endo- and epithelial permeability which is an early effect of the APR. Subsequently, the low nutrient concentrations may be maintained by other factors (described later; pp. 222-226), indicating that lower plasma concentrations are part of the APR and may have a protective function. If such 'apparent-deficient states' are protective, then administering large quantities of micronutrients at such times may upset this homeostasis. Table 2 illustrates examples of some adverse effects of nutrient supplementation in situations where an inflammatory environment may exist in vivo. This section will attempt to examine some of these issues and suggest explanations for the changes seen. Low plasma nutrient concentrations also occur in true nutrient-deficient states when the body maximises mechanisms for nutrient economy and possibly the same mechanisms operate in disease states.

\section{Vitamin A}

Hyporetinolaemia is an early feature of many infections (Reddy et al. 1986; Thurnham \& Singkamani, 1991; Louw et al. 1992), predominantly due to a reduced hepatic synthesis of retinol-binding protein (RBP; Rosales et al. 1996). $\mathrm{RBP}$, like transthyretin, albumin and transferrin, is a negative acute-phase protein (APP) and the rapidity of the response following infection suggests that the changes in RBP synthesis accompany those of the other APP initiated by cytokines IL- 1 and IL- 6 . The rapid fall in plasma retinol associated with infection may initially be due to an increased capillary permeability facilitating quicker distribution of retinol to tissues where it is needed to counter the infection. Labelling studies suggest that vitamin A in the extravascular pool is returned only slowly (37 d) to the plasma (Green \& Green, 1994); hence the recovery of plasma retinol concentrations following infection is dependent on a resumption of RBP synthesis and mobilisation from the liver.
Vitamin A has been known as the anti-infection vitamin for more than 50 years but its role in immune mechanisms is somewhat non-specific. Meta-analyses of eight major community vitamin A supplementation studies showed an overall reduction in mortality of $23 \%$ (Beaton et al. 1993) and vitamin A supplements have also been shown to reduce the severity of severe diarrhoea and to be vitally important for the treatment of measles (Barklay et al. 1987; Hussey \& Klein, 1990). However, the precise role of vitamin A in the immune response is still not known with certainty. As indicated elsewhere, retinoic acid is important for the control of cellular differentiation and this has important implications regarding the maintenance of epithelial tissues as barriers to infection and in the cellular expansion of immune cells following antigenic stimulation. Vitamin $\mathrm{A}$ is also involved in the activation of macrophages and may have a more specific role in T-cell-mediated responses and indirectly in the humoral response, i.e. the synthesis and secretion of immunoglobulins (Ross \& Hammerling, 1994; Ross, 1996, 1998). It was recently shown that 9 -cis-retinoic acid specifically enhances T-helper (Th) 2 development and that vitamin A deficiency biases the immune response in the Th1 direction (Stephensen et al. 2002b). It should be noted, also, that the active form of vitamin D, 1,25-dihydroxyvitamin D (calcitriol), has also been shown to be a potent inducer of monocytic differentiation (Kreutz \& Andreesen, 1990) and in this and many of its other functions, calcitriol appears to need retinoic acid to assist its binding to DNA and transcriptional functions (Gianna et al. 1996). For more detail, see the paragraphs later (p. 226) on vitamin D, and on vitamin A in the following section (p. 226).

\section{Vitamin C}

Evidence for changes in blood vitamin C concentrations associated with infection was first reported in the early 1970s when rapid falls in leucocyte ascorbate concentration were documented within $24 \mathrm{~h}$ of the onset of the common cold (Hume \& Weyers, 1973) or following surgery (Irvin et al. 1978). Leucocyte ascorbate concentrations normalised over the next 3-6 d and the changes were shown to be due to the rapid influx into the circulation of newly synthesised leucocytes, most of which were neutrophils and contained very little vitamin $\mathrm{C}$. Normalisation in leucocyte ascorbate concentrations can be accompanied by lower plasma concentrations (Vallance et al. 1978). The leucocytosis is of course a feature of the APR (Sipe, 1985) and the dilution of the resident polymorphonuclear leucocytes by the newly released, vitamin C-depleted polymorphonuclear leucocytes accounts for the apparent fall in leucocyte ascorbate concentration associated with stress conditions.

Plasma ascorbate concentrations are strongly linked to dietary intake and limited by a renal threshold of approximately $80 \mu \mathrm{mol} / 1$ (Friedman et al. 1941). In patients with disease, concentrations of plasma ascorbate are frequently lower than those seen in well-nourished subjects, but of course this may well be due to the anorexia of infection (Thurnham, 1990b). Nevertheless, administration of therapeutic doses of IL-2 to patients with malignancies produced a profound fall $(80 \%)$ in plasma ascorbate concentrations but the fate of the vitamin $\mathrm{C}$ in these patients is not known 
and plasma ascorbate concentrations returned to pre-treatment values when treatment was stopped (Marcus et al. 1991). While these changes in concentration may be due to a redistribution of vitamin $\mathrm{C}$ within the tissues, it would be interesting to know where the vitamin $\mathrm{C}$ was localised during treatment with IL-2.

The accumulation of ascorbate by neutrophils in response to stress (Moser \& Weber, 1984) is clearly a necessary part of neutrophil function as the ability is absent in the neutrophils of patients with chronic granulomatous disease and whose cells are unable to produce superoxide when stimulated (Washko et al. 1993). However, large supplements of vitamin $C(\geq 600 \mathrm{mg} / \mathrm{d}$ with and without vitamin E) can inhibit superoxide production (HerbaczynskaCedro et al. 1994, 1995; de la Fuente et al. 1998) while smaller amounts $(200 \mathrm{mg} / \mathrm{d})$ enhance it (Jayachandran et al. 2000). Thus, large vitamin $C$ supplements may be counterproductive to neutrophil free radical generation and cytotoxicity, although both high and low doses of supplementary vitamin $C$ have been found to increase neutrophil adherence and phagocytic capacity (de la Fuente et al. 1998; Jayachandran et al. 2000). The 'respiratory burst' is the index of phagocytic capacity, and is associated with increased NADPH oxidase (to generate superoxide) and myeloperoxidase activity (to convert $\mathrm{H}_{2} \mathrm{O}_{2}$ to hypochlorite). Bourgeois (2003) has suggested that ascorbate taken up by neutrophils protects NADPH oxidase and potentially increases its activity since it can react with superoxide to generate $\mathrm{H}_{2} \mathrm{O}_{2}$. Ascorbate does not destroy peroxide (Anderson \& Lukey, 1987); therefore ascorbate assists in the generation of hypochlorite by neutrophil meloperoxidase. The serum concentrations of ascorbate that Bourgeois (2003) referred to, however, ranged from 5 to $50 \mu \mathrm{g} / \mathrm{ml}$ (i.e. 30-300 $\mu \mathrm{mol} / \mathrm{l})$. Such serum concentrations cover the normal range and include concentrations likely to occur for a short time in individuals taking vitamin $\mathrm{C}$ supplements. The potential in vivo activity of ascorbate provides a rationale for its rapid uptake by the phagocyte at the start of infection.

Large doses of vitamin $\mathrm{C}$ administered at the time of inflammation will potentially aggravate oxidant damage within tissues (see the section on pro-oxidant properties of vitamin C; p. 231) and the uptake of ascorbate by neutrophils may provide a safe store for an important antioxidant and lower the risk of increasing inflammation at the site of trauma. However, in convalescent states, there are suggestions that vitamin $\mathrm{C}$ supplements may have beneficial effects (Herbaczynska-Cedro et al. 1995; Gokce et al. 1999; Wilkinson et al. 1999). Evidence suggests that vitamin $\mathrm{C}$ alters the redox state of arterial smooth muscle guanyl cyclase, thereby altering arterial sensitivity to NO (Murphy, 2002). Also, flow-mediated dilation of the brachial artery has been found to show a significant improvement post-treatment with vitamin C (Gokce et al. 1999). A progressive neutrophil leucocyte infiltration of damaged myocardium has been observed during the first $24 \mathrm{~h}$ after infarction. This is initially a beneficial process designed to remove damaged tissue. However, if the process continues it may exacerbate myocardial injury due to the over-production of reactive oxygen intermediates (ROI), and endothelial cells can be the primary target of immunological injury resulting in vasculopathy and organ dysfunction (Grech et al. 1996). As indicated earlier, vitamin $\mathrm{C}$ and $\mathrm{E}$ supplements increase neutrophil adherence, chemotactic and phagocytic capacity, coupled with a reduction in superoxide production (de la Fuente et al. 1998). Furthermore, $250 \mathrm{mg}$ vitamin $\mathrm{C}$ daily for 6 weeks was found to significantly reduce monocyte adhesion to endothelial cells in subjects with low compared with high concentrations of plasma ascorbate (mean 32 and $67 \mu \mathrm{mol} / 1$ respectively). Thus vitamin $\mathrm{C}$ (with or without vitamin $\mathrm{E}$ ) supplements in convalescent states such as coronary artery disease appear to improve blood flow through damaged tissues, reduce infiltration by monocytes and possibly reduce the net superoxide production from infiltrating neutrophils. That is, vitamin $\mathrm{C}$ supplements in the post-traumatic stage may assist the healing process, by promoting endothelial function.

\section{Vitamin D}

The active metabolite of vitamin $\mathrm{D}_{3}, 1 \alpha, 25$-dihydroxyvita$\min \mathrm{D}_{3}$ or calcitriol, has a central role in Ca homeostasis and most of the biological actions of calcitriol are mediated through its ability to bind to specific genes and modulate gene transcription. Calcitriol also displays profound antiproliferative, pro-differentiating and immunosuppressive properties (Lemire, 1995; Christakos et al. 1996) and, in many of its effects on gene transcription, calcitriol is believed to interact with retinoic acid, the active form of vitamin A. Vitamin A has long been known as the 'anti-infective vitamin' and emerging literature suggests that more attention should perhaps be directed at its interactions with vitamin $\mathrm{D}$ in understanding the immunological functions of vitamin A.

Calcitriol has prominent immunomodulatory properties (Lemire, 1992) and receptors for calcitriol have been identified on many cells of the haematolymphopoietic system (Hannah \& Norman, 1994). More than fifty gene products have been identified indicating metabolic involvement by vitamin $\mathrm{D}$ in mineral homeostasis, autoregulation of vitamin D metabolism, cell differentiation and proliferation, bone and extracellular matrix proteins, growth factors, hormones and others (Hannah \& Norman, 1994). Of particular interest are the interactions between vitamins $\mathrm{D}$ and $\mathrm{A}$ in gene transcription. The vitamin D receptor (VDR) binds to the vitamin D response element (VDRE) in the 5' flanking region of target genes but a number of reports have suggested that a nuclear accessory factor is required to assist binding to DNA and transcriptional function. Retinoid $\mathrm{X}$ receptor (RXR), which binds 9-cis-retinoic acid, is reported to assist binding of VDR to VDRE in some genes and evidence suggests that the VDR-RXR heterodimer is the functional transactivating species (Yu et al. 1991; Christakos et al. 1996). For more detail, see also the section on vitamin $\mathrm{A}$ and gene regulation (p. 226).

The primary source of calcitriol is the proximal convoluted tubular (PCT) cells in the kidney (Brunette et al. 2003). Studies using vitamin D-depleted animals support the endocrine role of parathyroid hormone-stimulated PCT in maintaining circulating levels of 1,25-dihydroxyvitamin $\mathrm{D}_{3}$ during vitamin $\mathrm{D}$ insufficiency. The renal synthesis of calcitriol is primarily responsible for $\mathrm{Ca}$ homeostasis by 
stimulating dietary $\mathrm{Ca}$ uptake by the gastrointestinal tract. In addition, since the PCT cells are the major site of $\mathrm{Ca}$ and phosphate absorption, local expression of vitamin D- $1 \alpha-$ hydroxylase probably also up regulates $\mathrm{Ca}$ receptor and sodium phosphate co-transport protein expression (Bland et al. 2001).

However, vitamin D-1 $\alpha$-hydroxylase activity has also been shown to be present in other tissues, for example, mature monocytes and macrophages, activated T and B lymphocytes (Provvedini et al. 1983) and cells in the more distal areas of the nephron (Bland et al. 2001). Experimental studies using cells from the distal region, namely a human cortical collecting duct line, have demonstrated that vitamin $\mathrm{D}-1 \alpha$-hydroxylase activity is increased under normocalcaemic conditions by added calciotropic regulators forskolin, calcitonin and parathyroid hormone, and that there is potent induction by bacterial lipopolysaccharide (LPS; Bland et al. 2001). It has also been shown that relatively high concentrations of extracellular $\mathrm{Ca}$ at sites of injury and infection may modify immune responses and enhance monocyte chemotaxis (Olszak et al. 2000). The synthesis of calcitriol may also be increased in such conditions.

Calcitriol has been reported by many workers to inhibit the proliferation of several human or murine promyelocytic leukaemia cells and promote the differentiation of the cells to the monocyte or macrophage phenotype (Abe et al. 1981; Miyaura et al. 1981; Nakamura et al. 1996). Such cells express the CD14 antigen, non-specific esterase activity and become plastic-adherent (Nakamura et al. 1996). The CD14 antigen is characteristic of monocytes and mediates the binding of LPS (Testa et al. 1993). It has been suggested that transforming growth factor- $\beta$ may potentiate the calcitriol-induced differentiation whereas alone it is largely ineffective (Testa et al. 1993). Following the culture of leukaemic cells lines treated with both calcitriol and transforming growth factor- $\beta$, CD14 antigen was comparable with that found on normal monocytes, while the production of adhesion molecules of the $\beta 2$-integrin family (CD11a, b and c) exceeded those produced by cells treated with calcitriol only.

Thus the production of calcitriol at sites other than the PCT cells appears to be responsive to infection and promote maturation and differentiation of the monocyte or macrophage. However, the clinical use of calcitriol or its analogues tends to be for its anti-inflammatory properties, for example, in the treatment of psoriasis (Kejian \& Mrowietz, 1998). Calcitriol and analogues of vitamin D have been shown to have immunosuppressive properties in autoimmune disease and organ transplantation (Lemire, 1995). This may be partly attributable to an inhibition of pro-inflammatory cytokine production (TNF- $\alpha$ and IL-6) by peripheral blood mononuclear cells (Shibaki et al. 1998) and a reduction in phagocytic activity (Spittler et al. 1997). However, others have reported calcitriol to promote phagocytosis and intracellular killing by macrophages (Bar-Shavit et al. 1981). In addition, evidence suggests that calcitriol inhibits the expression of B7.2 molecules, expressed on antigen-presenting cells to engage with the counter receptor, CD28, on T-cells. In this way calcitriol may inhibit the ability of monocytes and macrophages to induce T-cell activation (Lemire, 1995; Clavreul et al. 1998).

\section{Iron}

Nutritional deficiency of Fe results in anaemia, and growth may also be impaired. Both anaemia and poor growth are common in many developing countries, where both exposure to and rates of infection are particularly high. There are rapid falls in the plasma concentrations of $\mathrm{Fe}$ and $\mathrm{Zn}$ following the onset of infection and even before the onset of any fever. The greatest falls occur in those who subsequently develop fever (Pekarek et al. 1969; Beisel, 1976). The hypoferraemia of infection is accompanied by changes in plasma concentrations of several Fe-binding proteins (Thurnham \& Northrop-Clewes, 2003) that facilitate the uptake of Fe by the reticulo-endothelial system or removal and re-utilisation of $\mathrm{Hb}$ from effete erythrocytes. To understand the potential role of infection in contributing to $\mathrm{Fe}$ and $\mathrm{Zn}$ deficiencies, it is important to understand the purpose and possible functions of those pathological responses to infection that affect these minerals. For a discussion on the pro-oxidant properties of $\mathrm{Fe}$ and the potentially protective role of hypoferraemia, see p. 227 and 231.

Fe affects lymphocyte activation and proliferation and how macrophages handle Fe. The proliferative phase of lymphocyte activation is an Fe-requiring step as $\mathrm{Fe}$ is essential for enzymes such as ribonucleotide reductase, which is involved in DNA synthesis. Hence a large number of clinical studies have found reduced T-cell function in vivo as manifest by impaired skin-test reactions and reduced in vitro proliferation of T-cells in Fe-deficient individuals (Brock, 1993). The extent to which mild anaemia, the major problem in developing countries (Stoltzfus, 1997), impairs lymphocyte proliferation and impairs immune responses is more difficult to evaluate.

\section{Zinc}

$\mathrm{Zn}$ is an essential element for the functioning of more than 300 metalloenzymes, and the highly proliferative immune system is reliant on $\mathrm{Zn}$-dependent proteins involved in general cellular functions such as replication, transcription and signal transduction (Wellinghausen et al. 1997). In addition, experimental data suggest that $\mathrm{Zn}$ deficiency depresses the recruitment and chemotaxis of neutrophils, impairs natural killer cell activity, impairs phagocytosis by macrophages and neutrophils and impairs the generation of the oxidative burst (Rink \& Gabriel, 2000). Severe Zn deficiency, as described in the rare autosomal recessive disease acrodermatitis enterohepatica, is accompanied by thymic atrophy and a high frequency of bacterial, viral and fungal infections if not treated (Nelder \& Hambidge, 1975). Zn influences all immune cell subsets, but $\mathrm{Zn}$ is especially important in the maturation and function of $\mathrm{T}$ lymphocytes because $\mathrm{Zn}$ is an essential cofactor for the thymus hormone, thymulin (Wellinghausen et al. 1997). It is suggested that $\mathrm{Zn}$ deficiency influences Th1 more than Th2 cells. The production of interferon- $\gamma$, IL- 2 and TNF- $\alpha$ by Th1 cells is decreased, whereas the production of IL-4, IL- 6 and IL-10 by Th2 cells is not affected (Prasad, 1998). Th1 lymphocytes are important in cell-mediated immunity and responsible for IL- 2 and interferon- $\gamma$ release while Th 2 cells are linked to antibody-mediated immunity and the production 
of IL-4, IL-6, IL-10 and IL-13 (Prasad et al. 1997). The control of T-lymphocyte activation is delicately regulated by $\mathrm{Zn}$, and the physiological plasma $\mathrm{Zn}$ concentration of $12-16 \mu \mathrm{mol} / 1$ is optimally balanced for T-cell function (Wellinghausen et al. 1997).

With the onset of infection, plasma $\mathrm{Zn}$ concentrations fall rapidly; in febrile illness the fall can be as much as $70 \%$ (Beisel, 1976). About $65 \%$ of plasma $\mathrm{Zn}$ is bound to albumin and there is also a prompt fall in albumin and other proteins of a similar size after injury, due to an increase in microvascular permeability. However, albumin alone cannot account for the fall in plasma $\mathrm{Zn}$ concentrations, as the $\mathrm{Zn}$ :albumin concentration ratio falls by almost $50 \%$ (Fleck \& Myers, 1985). The main reason for the fall in plasma $\mathrm{Zn}$ concentrations is probably a consequence of monocyte stimulation by trauma or bacterial products, because experimental IL-1 infusions decrease plasma $\mathrm{Zn}$ concentrations and increase metallothionine transcription in hepatocytes (Moncada et al. 1991). During this APR, $\mathrm{Zn}$ is redistributed from the plasma to the liver and to lymphocytes (Beisel, 1995). The advantage to the host of this response may be deprivation of $\mathrm{Zn}$ from invading pathogens (Clohessy \& Golden, 1996). It is also important to note that while 12-16 $\mu \mathrm{mol} / \mathrm{l}$ is the optimal plasma $\mathrm{Zn}$ concentration for T-cell function in healthy subjects, higher concentrations can be inhibitory, thus a reduction in plasma $\mathrm{Zn}$ may be antiinflammatory (Wellinghausen et al. 1997). Workers have also shown that the mitogenic properties of $\mathrm{Zn}$, i.e. the direct induction by $\mathrm{Zn}$ of cytokine production in polymorphonuclear leucocytes, is enhanced by bacterial LPS and phytohaemagglutinin at concentrations of $\mathrm{Zn}$ which would not normally be mitogenic (Wellinghausen et al. 1997). Hence, while the early fall in plasma $\mathrm{Zn}$ concentrations in response to injury might be considered an immunological disadvantage, the presence of bacterial antigens together with low plasma $\mathrm{Zn}$ may in fact optimise T-cell stimulation.

Low plasma $\mathrm{Zn}$ concentrations $(<10.7 \mu \mathrm{mol} / \mathrm{l})$ have been associated with not only reduced growth and development, but also impaired immunity and increased morbidity from infectious diseases (Brown et al. 1998). The response to $\mathrm{Zn}$ supplements, however, is variable and may be dependent on whether plasma $\mathrm{Zn}$ concentrations reflect a true $\mathrm{Zn}$ deficiency or an infection-associated depression of plasma $\mathrm{Zn}$. A meta-analysis of supplementation studies in children below 13 years showed that overall there was a highly significant positive impact of $\mathrm{Zn}$ on change in weight (Brown et al. 1998). However, a review of eight randomised controlled intervention trials performed recently in less-developed countries found no evidence that maternal $\mathrm{Zn}$ supplementation promotes intra-uterine growth. There was evidence to suggest beneficial effects on neonatal immune status, early neonatal morbidity and infant infections. However, evidence was conflicting with respect to labour and delivery complications, gestational age at birth, maternal $\mathrm{Zn}$ status and health and fetal neurobehavioural development (Osendarp et al. 2003). However, Zn supplements have been shown to provide beneficial effects against diarrhoea (Zinc Investigators Collaborative Group, 2000) and this is possibly the best evidence of the widespread nature of $\mathrm{Zn}$ deficiencies in developing countries, as described below.
There is some evidence to suggest that an overproduction of intestinal NO may be responsible for the diarrhoea associated with Zn deficiency. Experimental studies show that inducible NO synthase (NOS) is elevated in the intestinal cells of $\mathrm{Zn}$-deficient compared with $\mathrm{Zn}$-adequate rats. A challenge with IL-1 $\alpha$ increased intestinal inducible NOS activity in all groups but inducible NOS expression was more marked and prolonged in the $\mathrm{Zn}$-deficient groups compared with other groups (Cui et al. 1997). Subsequently, the same workers (Cui et al. 1999) also showed that intestinal microvascular permeability (demonstrated by extravasation of Evans Blue) was greater in $\mathrm{Zn}$ deficient compared with $\mathrm{Zn}$-adequate rats. The administration of an inhibitor of inducible NOS for 2 weeks in the drinking water inhibited the extravasation of Evans Blue but not inducible NOS mRNA of the different groups of rats (Cui et al. 1999). Thus preventing the production of NO prevented extravasation produced by increased intestinal microvascular permeability, but not the increase in inducible NOS activity produced by Zn deficiency.

Adverse consequences of $\mathrm{Zn}$ supplementation have also been reported (Table 2). Fever was greater in patients on home parenteral nutrition with catheter sepsis who were given $\mathrm{Zn}$ supplements $(30 \mathrm{mg} / \mathrm{d})$ compared with those given 0 or $23 \mathrm{mg} / \mathrm{d}$ (Braunschweig et al. 1997). Depressed immune responses were observed in another study where patients were given 100-300 mg/d (Chandra, 1984). Likewise, the phagocytic and fungicidal activity of monocytes was impaired, and the duration of episodes of impetigo was increased in a group of marasmic infants who were given a $\mathrm{Zn}$-fortified formula in a double-blind controlled trial (Schlesinger et al. 1993). The results were seen between 60 and $150 \mathrm{~d}$ of $\mathrm{Zn}$ supplementation and suggest that $\mathrm{Zn}$ supplements even at the recommended dietary allowance level may impair monocyte function.

\section{Selenium}

Se status is assessed by the concentration in plasma or the activity of erythrocyte glutathione peroxidase (GPx). The latter is the better measure of functional status, while plasma concentrations reflect differences in the dietary intake as seen for example in Japanese individuals consuming different $\mathrm{Se}$ intakes in Japan and Brazil (Karita et al. 2001) and the increase in plasma Se in response to Se supplements (Greenman et al. 1988). Serum Se is also reported to be low in disease (Galloway et al. 2000; Maehira et al. 2002) and to be a sensitive predictor of survival in individuals with HIV (Baum et al. 2002). While low serum Se may indicate anorexia or low dietary intake during infection, recent experimental work suggests that as part of the APR to disease, there is a redistribution of body Se from the plasma and liver to the muscles and other tissues such as spleen and thymus (Maehira et al. 2002). Using hepatocytes, these workers also showed that the concentration of plasma Se found in human diseases (mean 0.82 (range $0 \cdot 36-1 \cdot 28) \mu \mathrm{mol} / \mathrm{l}$ ) was optimal for stimulation of the transcription factor NF- $\mathrm{KB}$, and synthesis of the APP, C-reactive protein $(0 \cdot 5-1 \cdot 0 \mu \mathrm{mol} / \mathrm{l})$. Se at physiological levels (1.54 (range 0.94-2.14) $\mu \mathrm{mol} / \mathrm{l}$ ) inhibits NF- $\kappa \mathrm{B}$ transcription (Maehira et al. 2003). Later in the section on pro- and 
antioxidants, the central role of NF- $\mathrm{KB}$ in coordinating the innate immune response is more fully discussed (p. 229).

However, not all the immunological properties of $\mathrm{Se}$ would appear to be optimal at the plasma concentrations found in disease. Others have shown that Se supplementation in patients with HIV is associated with an up regulation of IL-2 and increased activation, proliferation, differentiation and programmed cell death of Th cells. IL-2 is important for the generation of cytotoxic T-lymphocytes and for the activation and proliferation of natural killer cells. Cytotoxic T-lymphocytes are important for the recognition and removal of virus-infected cells, while natural killer cells are important for the non-specific killing of tumour cells (Baum et al. 2002). However, the apparently different requirements for Se for activation of $\mathrm{NF}-\kappa \mathrm{B}$ and $\mathrm{T}$-cell function may both be met by the redistribution of Se which takes place as part of the APR (Maehira et al. 2002). Concentrations of $\mathrm{Se}$ fall in the liver and plasma but increase in the spleen and thymus, tissues where Se is normally concentrated (McKenzie et al. 1998). The benefits of Se supplementation in HIV may be due to the prolonged nature of the disease and a high utilisation of Se.

$\mathrm{Se}$ is a constitutive component of the enzyme GPx. The enzyme exists in several isoforms, with slightly different functions, but is found in all tissues (Halliwell \& Gutteridge, 1985). One of the main functions of GPx is to convert lipid peroxides to the hydroxy acid and $\mathrm{H}_{2} \mathrm{O}_{2}$ to water. Thyrodoxin is a specific seleno-peroxidase found in the thyroid where it removes peroxides (Howie et al. 1998). Se deficiency partially blunts the thyroid response to I supplements (Zimmermann et al. 2003). The clinical effect of this may be that in children with both deficiencies, the combined deficiencies may worsen the goitrous condition and/or lead to its earlier appearance, although oral iodised oil is an effective method of I repletion in goitrous children. Experimental work has also shown that when $\mathrm{Se}$ is deficient, a high I intake may allow thyroid tissue damage due to a lack of Se-dependent GPx activity during thyroid stimulation (Hotz et al. 1997; Howie et al. 1998).

Disease and trauma are linked with increases in redox stress within tissues (Evans \& Halliwell, 2001) and experimental studies indicate that certain viruses may take advantage of compromised antioxidant status. Keshan disease in China is geographically associated with Se deficiency, but temporal fluctuations in incidence suggest that other factors are involved in its aetiology. Chinese workers suspected that enteroviruses, and particularly coxsackieviruses, were responsible for the cardiomyopathy; experimental studies showed that Se-deficient mice were more susceptible than Se-supplemented mice to the cardiotoxic effects of coxsackievirus B4 that had been isolated from the blood of a Keshan disease victim (Beck et al. 1994). These initial observations were explored by Beck and colleagues who found that susceptibility to these viruses was not specifically associated with Se deficiency but could also be increased by vitamin E deficiency or a combination of vitamin E deficiency and PUFA excess. Their work showed that a previously avirulent strain of coxsackievirus CVB3/0 was changed to a virulent phenotype when passaged through vitamin E-deficient animals (Beck et al. 1994). More recently, these workers have also reported that similar observations had been made in mice given excess Fe and in GPx'knock-out' mice (Beck, 1999). Analysis of the genomic structure of the newly developing viruses led Beck and colleagues to suggest that increased oxidative stress in disease facilitates the enhanced growth rate of the invading virus, increasing the probability of development of more virulent mutations (Beck \& Matthews, 2000). That is, it was not Se deficiency specifically which promoted the development of more virulent viruses, but impaired antioxidant status in appropriate tissues and cells.

\section{Micronutrients in gene expression}

Vitamin A and gene regulation

The process of cell differentiation takes place in all tissues through the body. It has been known for a long time that epithelial tissue differentiation was sensitive to vitamin A deficiency, as the normal mucous-secreting cells were replaced by keratin-producing cells. This is the basis of the pathological process termed xerosis that leads to the drying of the conjunctiva and cornea of the eye. The process can be reversed by treatment with vitamin $\mathrm{A}$ and it has become clear that vitamin A plays a hormone-like role in controlling the differentiation of cells in tissues and organs throughout the body.

Within tissues all-trans-retinol is in association with cellular RBP and can be oxidised to all-trans-retinoic acid and to 9-cis-retinoic acid. These oxidised forms of retinol are transported by cellular retinoic acid-binding proteins to the nucleus where they tightly bind to one or more nuclear receptors. There are two families of retinoic acid receptors (RAR and RXR) and three members of each family have been identified ( $\alpha, \beta$ and $\gamma$ ). Both the 9-cis- and all-transretinoic acids bind to the RAR members, while the most important ligand for RXR is the 9-cis isomer. When retinoic acid binds to the nuclear receptor, the complex regulates gene expression by binding to short sequences on DNA known as retinoic acid response elements or enhancers. The expression of the six receptors varies between cells but most, if not all, cells express at least one of the receptors. Several hundred genes have been shown to be induced or repressed by retinoids (Blomhoff, 1994).

\section{Vitamin $D$ and gene regulation}

The active form of vitamin $\mathrm{D}, 1,25$-dihydroxyvitamin $\mathrm{D}_{3}$ or calcitriol, also exerts its effects on gene transcription through the VDR. There are several different VDR alleles which are strongly linked to bone mineral density (Morrison et al. 1994). The calcitriol-VDR complex migrates to the nucleus where it binds to the VDRE in the 5 ' flanking region of target genes to elicit the appropriate transcriptional response. There are reports, however, that for many of the vitamin D-responsive genes, calcitriol works in association with vitamin A. RXR in accompaniment with 9-cis-retinoic acid is reported to assist the binding of VDR to VDRE and that the VDR-RXR heterodimer is the functional transactivating species (Yu et al. 1991; Christakos et al. 1996). The RXR and VDR are members of a super-family of transcription factors that become active 
after binding to their cognate ligands. The ligands for these receptors are small lipophilic molecules that include the steroid and thyroid hormones and the vitamins A and D (Mangelsdorf, 1994).

It is interesting to speculate whether the possible need for vitamin A to assist vitamin D-linked $\mathrm{Ca}$ absorption can explain the effect of oestrogen therapy in the prevention of bone loss in post-menopausal women (Gallagher, 2001). It was recently reported that while calcitriol up regulated transcellular Ca transport across Caco- 2 cells, $17 \beta$-oestradiol had no effect by itself and did not increase the effects of calcitriol when the two compounds were added together (Cotter \& Cashman, 2003). However, as mentioned earlier (p. 212), hormone-replacement therapy significantly increases plasma retinol by 15-20\% (Ballew et al. 2001). Concentrations of plasma retinol are normally tightly controlled and such an increase in circulating concentrations may have important effects at the cellular level, one of which might be an increase in tissue retinoic acid concentrations. Such effects in the elderly might be to increase the effectiveness of vitamin $\mathrm{D}$ in promoting $\mathrm{Ca}$ absorption and preventing bone loss. It would be interesting to see what effects the addition of 9-cis-retinoic acid might have on vitamin D-stimulated transepithelial $\mathrm{Ca}$ transport in Caco-2 cells.

\section{Genetic regulation of vitamin $C$ transport}

The evidence discussed earlier (p. 222) suggests that vitamin $\mathrm{C}$ has an important role in immune function and the rapid changes in tissue concentrations associated with infection suggest that mechanisms of tissue uptake are under the control of specific, infection-related factors. Man lacks the capacity to synthesise vitamin $\mathrm{C}$ because a nonfunctional gene is carried for the enzyme L-gulonolactone oxidase, which is required for the final step in the synthesis of ascorbate from glucose. However, it has recently been shown that, in common with the rat (an animal which does synthesise vitamin $\mathrm{C}$ ), we possess two genes which encode L-ascorbic acid transporter enzymes SVCT1 and SVCT2 (Wang et al. 2000). Both enzymes are extremely substrate specific and do not transport glucose. SVCT1 transport activity was found to be sensitive to extracellular pH (optimum $\mathrm{pH}$ about 7.5) that may affect the binding activity for L-ascorbic acid. Of particular interest also was the fact that tissue distribution tended to be organ specific. SVCT1 had a limited distribution, mainly confined to the bulk transporting epithelia such as the kidney and small intestine while SVCT2 displayed a much broader distribution in the brain, retina, spleen, leucocytes and in several endocrine and neuroendocrine tissues. The reason for the different distribution of the two forms is not yet known, but their distribution may suggest they are differentially regulated.

For example, recent work suggests that $\mathrm{Zn}$ induces osteoblastic differentiation by stimulating the expression of SVCT2 enzymes to enable vitamin C to traverse the membrane of the immature osteoblast from the extracellular space (Wu et al. 2003). The differentiation of osteoblasts requires the secretion of a type I collagen-containing extracellular matrix by osteoblast precursors and vitamin $\mathrm{C}$ is an essential vitamin for prolyl and lysyl hydroxylation necessary for the maturation of collagen peptide.
A further interesting aspect of the gene for SVCT1 is its localisation on chromosome 5, within a region that is commonly deleted in malignant myeloid diseases. It is suggested that its localisation raises the possibility that SVCT1 may play a role in tumour suppression, as there is evidence that L-ascorbic acid has cytotoxic effects on leukaemia cells in vitro (Iwasaka et al. 1998; Roomi et al. 1998).

In contrast to L-ascorbic acid, the oxidised form of vitamin C, dehydro-L-ascorbic acid (DHAA), enters cells via GLUT where it is then converted back to L-ascorbic acid (Root-Bernstein et al. 2002). Transport of DHAA by the GLUT mechanism is obviously influenced by the prevailing concentrations of plasma glucose. Root-Bernstein et al. (2002) suggest that diabetic neuropathy, retinopathy and nephropathy are a consequence of elevated DHAA concentrations, when plasma glucose concentrations rise so high that transport of plasma DHAA into cells is blocked. They suggest that cells in nerves, retina and kidney preferentially take up DHAA rather than L-ascorbate and, that in the face of elevated glucose concentrations, the uptake of DHAA is prevented. The cells are thus deprived of an essential antioxidant and pathologies develop. Interestingly, it was reported over 30 years ago that injections of DHAA into rats stimulated the release of insulin and lowered blood glucose. That is, DHAA may interact with insulin and glucose in a negative-feed-back manner to ensure that vitamin $\mathrm{C}$ activity is regenerated (Edgar, 1970). However, even if insulin production were impaired, DHAA is unstable and would be rapidly catabolised to 2,3-diketo-gulonic acid. The latter has no vitamin $C$ activity and its formation could lead to a gradual reduction in vitamin $\mathrm{C}$ status. Low plasma concentrations of ascorbate have been reported recently in newly diagnosed diabetics in two large surveys, and, while Will et al. (1999) maintain that the differences in vitamin C concentrations from control subjects disappear after correction for important covariates such as sex, age and dietary intake, others found that the differences still remained after correction (Sargeant et al. 2000). Further research in this area of cellular vitamin $\mathrm{C}$ transport is awaited with interest.

\section{Control of iron metabolism}

The regulation of Fe metabolism is normally under the control of Fe-regulatory proteins (IRP). These are cytoplasmic proteins that coordinate cellular $\mathrm{Fe}$ traffic by binding to sequences on mRNA known as Fe-responsive elements and protecting them from degradation. The mRNA involved encode proteins responsible for Fe uptake, storage and utilisation. As a consequence, in Fe deficiency IRP bind to mRNA and promote the expression of transferrin receptor protein while ferritin synthesis is repressed. Hence the utilisation and absorption of $\mathrm{Fe}$ is increased. When $\mathrm{Fe}$ is adequate, ferritin synthesis is promoted and Fe storage occurs (Hesketh et al. 1998).

TNF- $\alpha$ has an important role in Fe homeostasis since it: (a) induces expression of apoferritin mRNA and the synthesis of ferritin in adipocytes and muscle cells; (b) induces increased transferrin receptor mRNA and transferrin receptor protein in fibroblasts; (c) inhibits the release of Fe from peritoneal macrophages; (d) reduces the incorporation of plasma Fe into newly synthesised erythrocytes. The admin- 
istration of TNF- $\alpha$ to experimental animals leads to reduced serum Fe concentrations (Gordeuk et al. 1992), and a reduction of plasma $\mathrm{Fe}$ in the incubation period of most generalised infectious processes also occurs in man (Beisel, 1976)

In infection, the cytokines TNF- $\alpha$ and IL- 1 are increased and these reorganise the normal control of Fe metabolism. Plasma ferritin levels increase in spite of the hypoferraemia since ferritin mRNA is sensitive to both Fe and cytokines. It has been found that rat hepatoma cells exposed to IL-1 and TNF- $\alpha$ double the amounts of ferritin released into the medium over 24 and 48 h (Tran et al. 1997), and others have reported that $\mathrm{TNF}-\alpha$ in particular promotes ferritin translation, resulting in increased $\mathrm{Fe}$ storage in a human monocytic cell line (Fahmy \& Young, 1993). NO is also increased in infection and recent data suggest that NO may also have a direct role in the post-transcriptional gene regulation mediated by IPR. NO is produced both by macrophages in vivo as a physiological response to infection and by a variety of cell types as an intracellular messenger (Arroyo et al. 1992). In a low-Fe environment, interferon- $\gamma$, TNF- $\alpha$, IL- 1 or LPS induce macrophage NOS, and NO is central to macrophage-mediated cytotoxicity (Moncada et al. 1991). NO activates the mRNA-bonding activity of IRP and in this regard mimics the consequences of $\mathrm{Fe}$ starvation (Pantopoulos et al. 1994). NO-induced binding of IRP to Fe-responsive elements specifically represses the translation of transfected Fe-responsive element-containing indicator mRNA as well as the biosynthesis of the cellular Fe-storage protein, ferritin. These findings illustrate a regulatory connection between the NONOS pathway and cellular Fe metabolism (Weiss et al. 1993).

Hereditary haemochromatosis is a disease characterised by progressive Fe overload which, if undetected, can lead to cirrhosis, diabetes mellitus, cardiac disease, arthritis or hepatocellular carcinoma or a combination of these. The basic deficit appears to be an increase in Fe absorption, decrease in Fe excretion and production of preferential deposits of $\mathrm{Fe}$ in hepatic parenchymal cells rather than Kupffer cells. Recent evidence suggests that TNF- $\alpha$ may be involved in the aetiology of the disease because of its location on chromosome 6 and its effect upon Fe transport. The haemochromatosis gene is tightly linked to the HLA complex on the short arm of chromosome 6. TNF- $\alpha$, which is also located on chromosome 6 , down regulates Fe absorption and a lower production of TNF- $\alpha$ occurs in stimulated monocytes from patients with haemochromatosis in comparison with controls (Gordeuk et al. 1992; Conrad et al. 1994). Changes in $\mathrm{Fe}$ metabolism in haemochromatosis can be contrasted with those which occur during inflammation but authors caution that the lack of TNF is not necessarily opposite to the effects of increased TNF (Gordeuk et al. 1992).

\section{Implications of polymorphisms in the haptoglobin gene on vitamin $C$ and iron}

Serum haptoglobin (Hp) comprises two protein chains, and there are two forms of the $\alpha$ chain that differ by one amino acid giving rise to three variants of the $\mathrm{Hp}$ molecule in serum. Hp 1-1 comprises two $\alpha-1$ and two $\beta$ chains. Hp 1-2 comprises five proteins with different combinations of the three chains and Hp 2-2 comprises four variants of the $\alpha-2$ chain and one $\beta$ chain. It seems that Hp 1-1 has the best $\mathrm{Hb}$-binding capacity and because $\mathrm{Hp} 2-2$ binds $\mathrm{Hb}$ less well, certain aspects of the immune response are increased (see below) (Delanghe et al. 1998). Hp 2-2 appears to have spread from India and the distribution of the three forms is still not stable. Caucasians tend to have approximately 10-20\% Hp 1-1, blacks 30-50\% and Asians <10\%. The Hp 2-2 is most common in Asians (>50 \%), lowest in blacks and intermediate in Caucasians (Langlois \& Delanghe, 1996).

One phenotype of the $\mathrm{Hp}$ gene has been reported to influence vitamin $\mathrm{C}$ metabolism. The results indicate a lower stability of vitamin $\mathrm{C}$ (higher rate of ascorbic acid oxidation) in $\mathrm{Hp} \mathrm{2-2}$ carriers than the other two types, namely $\mathrm{Hp}$ 1-1 and $\mathrm{Hp} 2-1$. It has been shown there was less $\mathrm{Hp}$ in the blood of Hp 2-2 individuals. On the basis of this it has been suggested that there would be potentially more $\mathrm{Hb}-\mathrm{Fe}$ from effete erythrocytes present in serum causing the oxidation of ascorbate (Langlois et al. 1997).

Likewise, the same phenotype has also been reported to influence Fe metabolism. It was reported that both uninfected and HIV-infected individuals exhibiting the Hp 2-2 phenotype accumulated more Fe and had greater serum ferritin concentrations than those of the Hp 1-1 or 2-1 phenotypes (Delanghe et al. 1998). Thus possession of the Hp 2-2 phenotype may make individuals more susceptible to disease by lowering plasma vitamin $\mathrm{C}$ concentrations (although this might be viewed as protective; see the later section on pro-oxidants (p. 231)) and increasing potential inflammatory damage as a result of increased tissue Fe concentrations.

\section{Vitamin status and plasma homocysteine concentrations}

Recent work has shown that plasma concentrations of folic acid and vitamin $B_{12}$ and, to a lesser extent, riboflavin can influence plasma homocysteine concentrations. Folate intermediary metabolites are the primary source of one-carbon units for methylation and DNA synthesis and repair. Homocysteine is an important intermediate in the one-carbon cycle. Intracellular homocysteine is either converted to cysteine via the vitamin $\mathrm{B}_{6}$-dependent trans-sulfuration pathway or is re-methylated to methionine by the cobalamin-dependent methionine synthase (EC 2.1.1.13). The latter enzyme requires 5-methyl-THF as a methyl donor. If methionine synthase activity falls through a lack of vitamin $\mathrm{B}_{12}$ or of folic acid, the concentration of homocysteine increases (Fig. 1). This explains why vitamin $B_{12}$ and folic acid are major determinants of plasma homocysteine.

The formation of 5-methyl-THF is catalysed by the enzyme 5,10-methylene-THF reductase (MTHFR; EC 1.7.99.5) (Selhub, 1999). A commonly occurring C677T polymorphism of the MTHFR gene confers reduced enzyme activity and is associated with moderate increases in homocysteine, particularly in subjects with folate deficiency. Supplementation with folate in doses from 0.2 to $10 \mathrm{mg} / \mathrm{d}$ has been shown to reduce both normal and elevated plasma homocysteine concentrations (Ward, 2001). 
Riboflavin status has also been shown to influence plasma homocysteine concentrations, but the relationship is essentially confined to subjects with the C677T polymorphism of the MTHFR gene. Riboflavin is a precursor of FMN and FAD, which serve as cofactors for enzymes involved in the metabolism of vitamin $\mathrm{B}_{6}$, folate and cobalamin. Both riboflavin cofactors are involved in cobalamin metabolism through the enzyme methionine synthase reductase (EC 2.1.1.135). FMN is a cofactor for pyridoxine-5'-phosphate oxidase (EC 1.4.3.5) through which the active form of vitamin $\mathrm{B}_{6}$ is generated (pyridoxal-5'phospate), whereas FAD is a cofactor for MTHFR. MTHFR catalyses the formation of 5-methyl-THF, the methyl donor for methionine synthase. Pyridoxal-5'phospate is the cofactor for the enzyme which generates 5,10-methylene-THF, the latter being the substrate for both the MTHFR enzyme as well as thymidylate synthase. Riboflavin status was shown to influence homocysteine concentrations in healthy adult Norwegian blood donors (Hustad et al. 2000). These workers showed that plasma homocysteine concentrations were $1.4 \mu \mathrm{mol} / 1$ higher in the quartile with the lowest compared with highest riboflavin concentrations. This compared with a $2 \cdot 8 \mu \mathrm{mol} / \mathrm{l}$ difference between the highest and lowest quartiles for folate and $1 \cdot 0$ $\mu \mathrm{mol} / \mathrm{l}$ in the case of vitamin $\mathrm{B}_{12}$. However, the riboflavinhomocysteine relationship was essentially confined to subjects with the C677T polymorphism of the MTHFR gene. Riboflavin status was rated on the basis of plasma riboflavin concentrations, but no erythrocyte glutathione reductase stimulation tests were done. Erythrocyte glutathione reductase stimulation is a better discriminator of poor riboflavin concentrations than plasma riboflavin concentrations; it would be interesting to determine the effects of riboflavin supplements on plasma homocysteine concentrations in individuals or a population with riboflavin deficiency as assessed by erythrocyte glutathione reductase stimulation.

\section{Micronutrients as pro- and antioxidants}

\section{Antioxidant nutrients}

Cellular integrity. Disruptions to cellular integrity lead to the rapid release of cytokines by non-specific immune cells of the innate or natural immune system distributed through the body. The cytokines help to mount an inflammatory response and to recruit specialised cells such as mononuclear phagocytes, natural killer cells, neutrophils, etc to the site of damage or infection. It is now known that the rapid induction of the synthesis of these cytokines is coordinated by a common cellular element, a transcription factor known as $\mathrm{NF}-\kappa \mathrm{B}$.

$\mathrm{NF}-\kappa \mathrm{B}$ is critical for the inducible expression of many genes involved in the immune and inflammatory responses including IL- $1,-2,-6,-8$, TNF- $\alpha$, TNF- $\beta$, serum amyloid A protein, etc. It is reported that $\mathrm{NF}-\kappa \mathrm{B}$ exists in almost all cells but that it remains in the cytoplasm bound to an inhibitory protein, inhibitory $\mathrm{\kappa B}$. Exposure of cells to various inducers leads to the dissociation of the cytoplasmic complex and the translocation of the free $\mathrm{NF}-\mathrm{\kappa B}$ to the nucleus. In vitro studies have shown that phosphorylation accompanies the dissociation of the NF- $\kappa \mathrm{B}$-inhibitory $\kappa \mathrm{B}$ complex with a rapid degradation of the inhibitory $\mathrm{\kappa B}$ protein. Inducers, such as TNF- $\alpha$, can cause significant activation of NF- $\kappa \mathrm{B}$ within minutes, allowing NF- $\kappa \mathrm{B}$ to function as an effective signal transducer and rapidly connect events in the cytoplasm to response genes in the nucleus. One such response is the rapid up regulation of inhibitory $\kappa \mathrm{B}-\alpha$ synthesis, which then helps to shut down the NF- $\kappa B$ response and provide a uniquely suited feedback loop to sensitively control a transient inducer of responsive genes (Kopp \& Ghosh, 1995). However, a unique feature of signalling through NF- $\mathrm{KB}$ is the diversity of signalling molecules (viruses, ROI, mitogens, cytokines, etc) and situations that activate NF- $\kappa \mathrm{B}$ and the types of genes responsive to NF$\kappa \mathrm{B}$. Nevertheless, the common feature of the inducers is that they all signal situations of stress, infection or injury to the organism (Kopp \& Ghosh, 1995).

NF- $\kappa$ B can be activated by ROI (Schreck et al. 1992) and common inducers can be inhibited by antioxidants (Schreck et al. 1991). Thus the NF- $\mathrm{BB}$ mechanism is of particular interest to those wishing to account for the health advantages associated with antioxidant-rich fruit and vegetable diets. $N$-Acetyl-L-cysteine is a precursor of the antioxidant GSH and a scavenger of ROI, and suppresses the activation of NF- $\kappa \mathrm{B}$ by many agents. This supports the idea that the redox state of the cell plays a general role in the activity of NF-KB (Schreck et al. 1991, 1992; Kopp \& Ghosh, 1995). However, in vitro studies with micronutrients which influence the redox state have to be carefully interpreted (Erickson et al. 2000). In neutrophils, deficiencies of $\mathrm{Fe}$ can reduce myeloperoxidase activity (Keith \& Jeejeebhoy, 1997) and supplements of vitamins C and E suppress the production of oxygen free radicals (de la Fuente et al. 1998). Thus potentially both dietary deficiency and dietary excess can reduce the oxidant activity of neutrophils, thereby disrupting the coordination of the inflammatory response, impairing the killing of bacteria and/or reducing tissue damage. Among the questions that need to be answered, are: is there an optimal redox state in vivo to enable efficient bacterial killing with minimal damage to surrounding tissues (Erickson et al. 2000) and are certain antioxidant nutrients more important than others in regulating this state? (See earlier discussion on Se pp. 225-226.)

Vitamin E. Vitamin E falls into the class of conventional antioxidants, which are generally phenols or aromatic amines. The amount of vitamin $\mathrm{E}$ in membranes is several thousand times less than the amount of potentially oxidisable lipid (Kornbrust \& Mavis, 1979). Under oxidative stress, vitamin E undergoes a very rapid transfer of phenolic hydrogen to the recipient free radical with the formation of a resonance-stabilised phenoxyl radical from the vitamin E. The phenoxyl radical is relatively unreactive towards lipid or oxygen and therefore does not propagate the chain reaction. However, the phenoxyl radical is no longer an antioxidant and to maintain the antioxidant properties of membranes, the vitamin E must be regenerated (Chaudiere \& Ferrari-Iliou, 1999). Water-soluble vitamin C is the popular candidate for this role (Packer et al. 1979), but thiols and particularly GSH can also function in vitro (Niki et al. 1982; Wefers \& Sies, 1988; Chaudiere \& Ferrari-Iliou, 1999). 
Vitamin $C$. Ascorbic acid is a powerful reducing agent and many, if not all, of the biological properties of vitamin $\mathrm{C}$ are linked to its redox properties. For example, the essential defects in scurvy such as the breakdown of connective tissue fibres (Myllyla et al. 1978) and muscular weakness (Hulse et al. 1978) are both linked to hydroxylation reactions, the activity of which requires ascorbate to maintain loosely bound $\mathrm{Fe}$ in the ferrous form. Oxidation of the $\mathrm{Fe}$ to its ferric form inactivates the enzymes (Bates, 1981). The possible role of $\mathrm{Zn}$ status in these interactions may also need to be considered in view of its role in inducing SVCT2 enzyme activity in osteoblast differentiation (Wu et al. 2003). In the eye, vitamin $C$ concentrations are about fifty times higher than those in the plasma and may protect against the oxidative damage of light (Koskela et al. 1989). Vitamin C displays redox functions in catecholamine biosynthesis (Bates, 1981) and spermatogenesis may also need ascorbate to protect DNA from oxidative damage (Fraga et al. 1991). Spermatogenesis needs many more cell divisions than oogenesis, and it is suggested that DNA damage varied inversely with the intake of vitamin $\mathrm{C}$ between 5 and $250 \mathrm{mg} / \mathrm{d}$ (Fraga et al. 1991). Frei (1991) has also shown that vitamin $\mathrm{C}$ was superior to all other biological antioxidants in protecting plasma lipids exposed $e x$ vivo to a variety of sources of oxidant stress. Last, plasma vitamin $\mathrm{C}$ may protect plasma folate concentrations; thus it should be inversely associated with plasma homocysteine concentrations. Jacques et al. (1995) reported that dietary vitamin $\mathrm{C}$ intakes were inversely associated with plasma homocysteine concentrations in older individuals in the Framingham study and suggested that this is probably largely due to a strong positive association between vitamin $\mathrm{C}$ intake and plasma folate concentrations.

Carotenoids. The carotenoids have a general structure comprising two six-membered $\mathrm{C}$ rings separated by eighteen $\mathrm{C}$ atoms usually in the form of a conjugated chain of double bonds. The chemical properties of the carotenoids closely relate to the extended system of conjugated double bonds and the various functional groups on the terminal ring structures. Although there are many hundreds of carotenoids found in nature, there are relatively few found in human tissues, the five main ones being $\beta-C, \alpha$-carotene, lycopene, $\beta$ cryptoxanthin and lutein (Thurnham, 1994a). The ROI scavenged by carotenoids are peroxyl radicals (Burton \& Ingold, 1984; Palozza \& Krinsky, 1992), and carotenoids in general, and lycopene specifically, are very efficient at quenching singlet oxygen (Foote \& Denny, 1968; Di Mascio et al. 1989). Singlet oxygen is generated during photosynthesis, therefore carotenoids are important in protecting plant tissues, but there is limited evidence for this role in man. However, $\beta-\mathrm{C}$ has been used in the treatment of erythropoietic protoporphyria with some success, which is a light-sensitive condition where singlet oxygen might be involved in the pathogenesis (Mathews-Roth, 1986). Otherwise, results from studies suggesting that $\beta-C$ provides protection against solar radiation are somewhat equivocal. There was no benefit reported when large amounts of $\beta-\mathrm{C}$ were used to treat individuals with a high risk of non-melanomatous skin cancer (Greenberg et al. 1990). However, two carotenoids (lutein and zeaxanthin) which occur specifically associated with the rods and cones in the eye (Bone et al. 1988) may protect the retinal pigment epithelium against the oxidative effects of blue light (Gerster, 1991).

The antioxidant properties of carotenoids depend on oxygen tension in the surrounding tissue. At low oxygen tension, $\beta-\mathrm{C}$ acts as a chain-breaking antioxidant whereas at high oxygen tension it readily auto-oxidises and exhibits pro-oxidant behaviour (Burton \& Ingold, 1984). Palozza (1998) reviewed much of the evidence and suggested that $\beta-\mathrm{C}$ has antioxidant activity between 2 and $20 \mathrm{mmHg}$ oxygen tension, but in air or when oxygen tension is $>150 \mathrm{mmHg}$, it is much less effective and can show prooxidant activity as the oxygen concentration increases. The widespread distribution of carotenoids in plants, and the considerable epidemiological evidence that consumption of fruit and vegetables was protective against heart disease, led to three major $\beta-C$ intervention studies (World Health Organization, 1990). In two of these (ATBC, CARET) the subjects were smokers or individuals who had previously been exposed to asbestos (Heinonen et al. 1994; Rowe, 1996). In both there was excessive mortality from lung cancer in the $\beta$-C-treated groups. In the third study (Physicians' Study), the subjects were not primarily smokers and the overall conclusion was that $\beta-C$ caused neither benefit nor harm (Hennekens et al. 1996). The evidence that $\beta-C$ may induce $\mathrm{P} 450$ enzymes that activate known pro-carcinogens (Paolini et al. 1999) is discussed in the section on smoking (p. 219).

Flavonoids and polyphenols. Polyphenols are compounds which, by definition, are made up from multiple phenol rings. They can be split into two groups; flavonoids and non-flavonoids. Flavonoids are the most common and widely distributed group of phenolics with over 4000 individual flavonoid compounds known to occur in nature (Harbourne, 1994). Structurally they comprise a minimum of at least two phenol moieties linked via a pyran ring. They can be free or polymerised or linked to sugars or other non-flavonoid phenols. Dietary sources of flavonoids are predominantly fruits and vegetables, or products derived from these foods, such as wines and fruit juices. The simpler flavonoids tend to be water soluble and are usually conjugated with various sugars in the form of glycosides. Cooking usually has little effect on the glycosides but colonic bacterial $\beta$-glycosidases will hydrolyse the glycosidic link, releasing the aglycone. The aglycones tend to be insoluble and, to be absorbed, must be conjugated to glucuronide or sulfate groups by phase II enzymes (see the section on nutrients and metabolism of drugs; p. 217).

Quercetin is a major flavonol (a sub-class of the flavonoids) which is found ubiquitously in the diet (Hertog et al. 1993). There is much evidence to suggest that it is a powerful bioactive constituent of the human diet with powerful antioxidant activity and free-radical scavenging properties (Ramanathan et al. 1994; Terao et al. 2001). However, most of the work carried out on quercetin has been done on the aglycone as substrate. It is only recently that the identification of quercetin metabolites has been reported, namely quercetin-3-glucuronide, 3'-methylquercetin-3-glucuronide and quercetin-3'-sulfate (Day et al. 2001). In this report, about $80 \mathrm{mg}$ of metabolites (expressed 
as the aglycone equivalent) were recovered after feeding $200 \mathrm{~g}$ onion to four volunteers. Only about $0.01 \%$ quercetin was found in plasma as the aglycone. While some of the metabolites found will retain the biological properties of the aglycone, others will not and much work needs to be done to re-evaluate the previous experimental work done with flavonoid aglycones to characterise the important metabolites in man and their biological activity.

As indicated earlier, an adequate dietary intake of polyphenolics is important for their potential beneficial effects in reducing chronic disease. Such effects may be exerted, for example, via their influence on P450 enzymes, potentially preventing the bioactivation of dietary pro-carcinogens. However, there are disadvantages in vegetarian diets in that some phenolic compounds will bind mineral ions, for example $\mathrm{Fe}, \mathrm{Zn}$, $\mathrm{Ca}$, etc, and prevent absorption (Hallberg \& Hulthen, 2004). In addition, the converse is probably also true, that mineral supplements such as $\mathrm{Fe}$ and $\mathrm{Ca}$ that bind to polyphenols will also prevent the absorption of polyphenols ( $\mathrm{R}$ Welsh, unpublished results).

\section{Pro-oxidant nutrients}

Most biological antioxidants are potentially pro-oxidants. When an antioxidant molecule accepts an unpaired electron from a free radical, the intermediate formed by the antioxidant becomes itself a free radical. Fortunately, this is mainly a problem for food chemists (Pokorny et al. 2001) and does not appear to be a major problem in the human body. However, in the case of vitamin $\mathrm{C}$, changes in plasma concentrations occur which may be linked to its potential to be a pro-oxidant in inflammatory conditions. Likewise, $\mathrm{Fe}$ in healthy subjects is carefully controlled by binding to a variety of proteins in plasma and tissues and is unlikely to have pro-oxidant effects. However, in inflammation and disease, changes occur in the handling of Fe which can be interpreted as a way of minimising potential pro-oxidant effects, and these will be described later (p. 232).

Inflammation and vitamin $C$. During inflammation, several metabolic changes are activated which depress the concentration of some vitamins with antioxidant properties, especially vitamin C. Within 24 h of surgery (Irvin et al. 1978; Vallance, 1986) or following an attack of influenza (Hume \& Weyers, 1973), leucocyte vitamin C concentrations are depressed. This apparent depression is due to the mobilisation of new neutrophils from bone marrow, which enter the circulation with low to absent concentrations of ascorbate (Irvin et al. 1978; Vallance, 1986). The depression continues for 3 to $5 \mathrm{~d}$ while the cells gradually acquire vitamin $\mathrm{C}$, probably from the plasma. Several workers have shown that granulocytes will actively take up ascorbate in vitro (Evans et al. 1982; Moser \& Weber, 1984; Wang et al. 1997) and where residual inflammation remains, plasma ascorbate concentration tends also to be low (Vallance et al. 1978; Riemersma et al. 2000). It has been suggested that granulocytes require the ascorbate to protect them from free radical products that they produce during phagocytosis (Hemila et al. 1984).

An alternative reason why plasma ascorbate concentrations fall in the presence of inflammation may be to reduce the risk of oxidation of transition metals. In vivo, ascorbic acid is an antioxidant but some transition metals, for example the higher valency states of $\mathrm{Fe}$ and $\mathrm{Cu}$, are thermodynamically more easily reduced than ascorbate, hence any non-protein-bound $\mathrm{Fe}^{3+}$ or $\mathrm{Cu}^{2+}$ are reduced to $\mathrm{Fe}^{2+}$ and $\mathrm{Cu}^{+}$respectively by the presence of ascorbate. However, non-protein-bound transition metals rarely occur in healthy blood and tissues, but in damaged tissues such metals can occur in the emerging fluids (Chevion et al. 1993), and the formation of the ferrous ion is potentially very damaging for tissues. Ferrous Fe in particular is a powerful catalyst of the Haber-Weiss and Fenton reactions that form hydroxyl radicals with potentially damaging consequences for any molecule in the vicinity (reactions 4 and 5; p. 232).

Ascorbate frequently catalyses damage in tissues in vitro probably because any tissue preparation is likely to be contaminated with unbound Fe. This may be the explanation for the recent suggestion that ascorbate and many of its derivatives have anti-cancer properties (Roomi et al. 1998). In vitro experiments with a malignant leukaemia cell line (P388D1) suggested that the concentration of ascorbate that inhibited cell growth by $50 \%$ was approximately $17 \mu \mathrm{mol} / 1$. Mean concentrations of plasma ascorbate tend to fall in the range of 11-20 $\mu \mathrm{mol} / 1$ in populations where there is a risk of chronic disease, for example, the elderly (Department of Health and Social Security, 1979). Mean concentrations of plasma ascorbate also tend to fall where there is an increased exposure to disease, for example in the rainy season in developing countries (Bates et al. 1982; Knowles et al. 1991). Of course, plasma ascorbate concentrations are also strongly correlated with the dietary intake of vitamin C, but healthy populations do tend to have higher concentrations of plasma ascorbate than those exposed to sickness or trauma or who are sick (Thurnham, 1994b).

Other workers have suggested that the cytotoxic properties of the ascorbate derivatives against human tumour cell lines is due to their ability to generate $\mathrm{H}_{2} \mathrm{O}_{2}$ (Iwasaka et al. 1998) and have shown that the cytotoxic activity of sodium ascorbate was almost completely inhibited by the addition of catalase to the assay. In any case, the generation of $\mathrm{H}_{2} \mathrm{O}_{2}$ by sodium ascorbate is probably due initially to the reaction of ascorbate with transition metals in the medium, i.e. it is an artefact of the experimental conditions (see also p. 223. Nevertheless, the treatment of cancer is often aggressive and likely to cause inflammation as indicated by the usefulness of Fe chelators to lessen the side-effects of chemotherapy (Beare \& Steward, 1996). However, the use of large amounts (up to $45 \mathrm{~g}$ ) of vitamin $C$ to treat cancer has not been successful (Cameron \& Campbell, 1974); it was later pointed out that the deaths of four patients from haemorrhagic tumour necrosis soon after treatment was started may have been due to the pro-oxidant effects of vitamin C (Halliwell, 1994) (Table 2).

Transition metals. In the absence of inflammation, $\mathrm{Zn}$, $\mathrm{Cu}, \mathrm{Mg}$ and Se are intimately involved in protecting the body against oxidative stress. Superoxide dismutase is found in all aerobic cells and is responsible for the dismutation of the free radical superoxide (reaction 1). In the cytoplasm, $\mathrm{Zn}$ and $\mathrm{Cu}$ are cofactors, while in the mitochondria, $\mathrm{Zn}$ and $\mathrm{Mg}$ work together to produce $\mathrm{H}_{2} \mathrm{O}_{2}$.

$$
\mathrm{O}_{2}^{\cdot-}+\mathrm{O}_{2}^{\cdot-}+2 \mathrm{H}^{+}=\mathrm{H}_{2} \mathrm{O}_{2}+\mathrm{O}_{2}
$$

(Reaction 1) 
The $\mathrm{H}_{2} \mathrm{O}_{2}$ produced as a product of the dismutation reaction is removed by GPx, a Se-dependent enzyme. To reduce $\mathrm{H}_{2} \mathrm{O}_{2}$ to water, the enzyme uses GSH as a source of hydrogen (reaction 2). Cellular concentrations of glutathione are maintained by the enzyme glutathione reductase, which is a riboflavin-dependent enzyme.

$$
\mathrm{H}_{2} \mathrm{O}_{2}+2 \mathrm{GSH}=\mathrm{GSSG}+2 \mathrm{H}_{2} \mathrm{O}
$$

Superoxide dismutase and GPx are widely distributed in aerobic tissues and, if no catalytic metal ions are in the vicinity, endogenously produced superoxide and $\mathrm{H}_{2} \mathrm{O}_{2}$ at physiological concentrations have limited, if any, damaging effects (Halliwell et al. 1992). However, during inflammation and disease, tissue structures break down, and in these conditions transition metals which are normally tightly bound to proteins and other subcellular structures are freed (Chevion et al. 1993; Beare \& Steward, 1996) and are potentially able to generate the hydroxyl radical $(\mathrm{OH})$ by the Haber-Weiss reaction (reaction 3 ) or the Fenton reaction (reaction 4). Pathological conditions greatly increase the concentrations of both superoxide and $\mathrm{NO}$, and the formation of the toxic intermediate peroxynitrite (ONOO) with the reactivity of the hydroxyl radical (reaction 5) has been demonstrated in macrophages, neutrophils and cultured endothelium (Koppenol et al. 1992; Carreras et al. 1994).

$$
\begin{aligned}
& \mathrm{Fe}^{2+}+\mathrm{H}_{2} \mathrm{O}_{2}=\mathrm{Fe}^{3+}+\mathrm{OH}^{-}+\mathrm{OH}^{-} \\
& \mathrm{O}_{2}^{\cdot-}+\mathrm{H}_{2} \mathrm{O}_{2}=\mathrm{O}_{2}+\mathrm{OH}^{\cdot}+\mathrm{OH}^{-} \\
& \mathrm{NO}+\mathrm{O}_{2}^{\cdot-}=\mathrm{ONOO}
\end{aligned}
$$

Depressed serum Fe concentrations develop abruptly during the incubation period of most generalised infectious processes (Beisel, 1976). This can be viewed as a measure by the body to reduce $\mathrm{Fe}$ availability for pathogenic bacteria and counter potential pro-oxidant damage. The body alters the transport and distribution of $\mathrm{Fe}$ by blocking $\mathrm{Fe}$ mobilisation and stimulating Fe uptake from plasma by the liver, spleen and macrophages (Thurnham, 1990b, 1995; Weiss et al. 1995). In addition, NO has been shown to play a role in the coordination of Fe traffic by mimicking the consequences of $\mathrm{Fe}$ starvation and leading to the cellular uptake of Fe (Pantopoulos et al. 1994). These changes in the control of Fe traffic are part of a generalised response known as the APR which in the short term is considered protective (Thompson et al. 1992). For further discussion on the control of $\mathrm{Fe}$ traffic, see the earlier section on micronutrients in gene expression (p. 227).

It was initially suggested that the hypoferraemia of infection protected the host by reducing the Fe available for bacterial growth (Weinberg, 1984), and certainly the overwhelming infections resulting in deaths in a number of malnourished children who received Fe would support that view (McFarlane et al. 1970) (Table 2). However, while some bacteria may benefit from $\mathrm{Fe}$ supplements, other pathogenic bacteria have powerful siderophores enabling them to compete quite successfully against the Fe-binding proteins in the plasma (Bullen, 1981). The importance of the hypoferraemia therefore may be more closely linked with its potential influence on the redox status in the tissues (Thurnham, 1997b). Hypoferraemia may protect against the potential pro-oxidant properties of $\mathrm{Fe}$ and the exacerbation of tissue damage at sites of inflammation (Thurnham, $1990 b)$. In this connection it is interesting to point out that lactoferrin is secreted by neutrophils at sites of inflammation. Lactoferrin has a higher affinity for Fe than transferrin and can also bind $\mathrm{Fe}$ under acid conditions, such as those found at sites of inflammation (Bullen, 1981). Thus a reduction in plasma ascorbate and Fe can be viewed as a physiopathological response to the potential pro-oxidant conditions that can arise as a result of inflammation and disease. Reactive oxygen species generation is an important part of human defences in malaria and other diseases (Reibnegger et al. 1987) and malaria is possibly a good example of where pro-oxidant conditions coupled with $\mathrm{Fe}$ supplements may worsen the disease outcome (Table 2).

Withholding $\mathrm{Fe}$ from the circulation will eventually cause anaemia, which is very common in developing countries. Both dietary and infection-related factors contribute to this (Walter et al. 1997). Frequent infections reduce circulating $\mathrm{Fe}$ and increase the risk of anaemia. Infection reduces appetite and fever blocks Fe absorption (Beresford et al. 1971). In Papua New Guinea, infants whose $\mathrm{Hb}$ at birth was highest and those given iron dextran at birth were more likely to be admitted to hospital with severe malaria than infants not given $\mathrm{Fe}$ and with a low $\mathrm{Hb}$ at birth (Oppenheimer, 1989). These observations were made during a study on Fe supplementation to infants at birth, living in an area where there was a high prevalence of malaria (Oppenheimer et al. 1986); yet, a similar study in the same area in schoolchildren did not find any adverse consequences of an Fe supplement on malaria prevalence (Harvey et al. 1989). Age may be an important factor to consider in the case of Fe, since cell-mediated immunity is the first form of defence against disease in infants and other non-immune individuals (Reibnegger et al. 1987), while schoolchildren living in a malaria-endemic area would be able to mount a humoral response, and cell-mediated immunity may be less active in such children. Thus the undesirability of high levels of $\mathrm{Fe}$ in its various forms in plasma may be of far greater importance in the infant where anti-malarial defence is more dependent on generating reactive oxygen species by phagocytes, than in the schoolchild.

Thus the hypoferraemia of infection may be a defensive strategy developed initially to protect the non-immune infant and, because of its success, it continues into adulthood even though its importance becomes superseded by humoral immunity as we get older.

\section{Conclusions}

Many micronutrients are potentially vulnerable to the effects of prescribed medicines when consumption is regular and sustained. Thus the elderly are particularly at risk of some micronutrient deficiencies such as thiamin, folate and vitamins $C$ and $D$, whilst the intake of nutrients such as vitamin $\mathrm{K}, \mathrm{Fe}$ and folate may have to be regulated carefully to avoid reducing the efficiency of some therapies. Lifestyle factors such as smoking, alcohol and tea consumption and general dietary habits certainly influence micronutrient status and may have a conditioning effect on health status. 
Alcohol abuse can specifically induce thiamin deficiency but the consumption of any substance, especially if consumed regularly and in large amounts, can influence the biotransformation of dietary substances and have a much wider impact on the metabolism of xenobiotic compounds that may influence our risks of chronic disease.

There are profound effects of infection on certain micronutrients. Our bodies respond to infection by a rapid series of changes over 24 to $48 \mathrm{~h}$ that are collectively termed the APR. The concentrations in the blood of several nutrients including vitamin $\mathrm{A}$, vitamin $\mathrm{C}, \mathrm{Fe}$ and $\mathrm{Zn}$ fall acutely during this period. Changes occurring during the APR are generally considered to be beneficial to the host and there are possible advantages resulting from the falls in micronutrient concentrations.

There are many interactions between micronutrients and genes. Nutrients such as vitamin A have been recognised for some time to exert metabolic effects through a direct effect of all-trans- or 9-cis-retinoic acid on response elements in DNA, alone or in concert with other substances, and influence a number of different genes. Vitamin D also exerts its effects through response elements and, in some if not all of its actions, it works in concert with vitamin A. Not only does vitamin D influence Ca homeostasis through this mechanism, it also has important effects on immune mechanisms. While we may have lost the ability to synthesise vitamin $\mathrm{C}$, we possess two genes which exert control over vitamin $\mathrm{C}$ transport in different tissues and may have important implications in the movement of vitamin $\mathrm{C}$. $\mathrm{Fe}$ uptake, storage and utilisation is very tightly controlled by IRP which bind to and stabilise mRNA. Infection, however, can very powerfully override the control of Fe metabolism and produce a state which is akin to $\mathrm{Fe}$ deficiency. Polymorphisms of different genes can also influence vitamin $\mathrm{C}, \mathrm{Fe}$ and folate metabolism.

Antioxidant nutrients are potentially pro-oxidant nutrients but the latter properties are not evident in vivo unless tissue integrity is compromised, as in disease. The redox status of the cell is one of the important factors influencing the transcription factor $\mathrm{NF}-\kappa \mathrm{B}$ which coordinates cytokine release and the recruitment of specialised immune cells to the site of damage or infection. There is a growing body of evidence that antioxidant status is closely linked to cellular integrity and that it is an important regulator of cellular function, especially in disease.

\section{References}

Abe E, Miyaura C, Sakagami H, Takeda M, Konno K, Yamazaki T, Yoshiki S \& Suda T (1981) Differentiation of mouse myeloid leukemia cells induced by 1 $\alpha, 25$-dihydroxyvitamin $\mathrm{D}_{3}$. Proceedings of the National Academy of Sciences $\mathbf{7 8}$, 4990-4994.

Akompong T, Eksi S, Williamson K \& Haldar K (2000a) Gametocytocidal activity and synergistic interactions of riboflavin with standard antimalarial drugs against growth of Plasmodium falciparium in vitro. Antimicrobial Agents and Chemotherapeutics 44, 3107-3111.

Akompong T, Ghori N \& Haldar K (2000b) In vitro activity of riboflavin against the human malaria parasite Plasmodium falciparum. Antimicrobial Agents and Chemotherapeutics 44, 88-96.
Alonso-Aperte E \& Varela-Moreiras G (2000) Drug-nutrient interactions: a potential problem during adolescence. European Journal of Clinical Nutrition 54, S69-S74.

Amatayakul K, Underwood BA, Ruckphaopunt S, Singkamani R, Linpisarn S, Leelapat P \& Thanangkul O (1989) Oral contraceptives: effect of long-term use on liver vitamin A storage assessed by the relative dose response. American Journal of Clinical Nutrition 49, 845-848.

Anderson R \& Lukey PT (1987) A biological role for ascorbate in the selective neutralization of extracellular phagocyte-derived oxidants. Annals of the New York Academy of Sciences 498 229-247.

Arroyo PL, Hatch-Pigott V, Mower HF \& Cooney RV (1992) Mutagenicity of nitric oxide and its inhibition by antioxidants. Mutation Research 281, 193-202.

Ballew C, Bowman BA, Sowell AL \& Gillespie C (2001) Serum retinol distribution in residents of the United States: third National Health and Nutrition Examination Survey, 1988-1994. American Journal of Clinical Nutrition 73, 586-593.

Barklay AJG, Foster A \& Sommer A (1987) Vitamin A supplements and mortality related to measles: a randomised clinical trial. British Medical Journal 294, 294-296.

Bar-Shavit Z, Noff D, Edelstein SL, Meyer M, Shibolet S \& Goldman R (1981) 1,25-Dihydroxyvitamin $\mathrm{D}_{3}$ and the regulation of macrophage function. Calcified Tissue International $\mathbf{3 3}$, 673-676.

Barton JC, McDonnell SM, Adams PC, Brissor P, Powell LW, Edwards CQ, Cook JD, Kowdley KV \& the Hemochromatosis Management Working Group (1998) Management of hemochromatosis. Annals of Internal Medicine 129, 932-939.

Bates CJ (1981) The function and metabolism of vitamin C in man. In Vitamin C - Ascorbic Acid, pp. 1-22 [JN Counsell and DH Hornig, editors]. London: Applied Science Publishers.

Bates CJ, Prentice AM, Paul AA \& Whitehead RG (1982) Seasonal variations in ascorbic acid status and breast milk ascorbic acid levels in rural Gambian women in relation to dietary intake. Transactions of the Royal Society of Tropical Medicine and Hygiene 76, 341-347.

Baum MK, Miguez-Burbano MJ, Campa A \& Shor-Posner G (2002) Selenium and interleukins in persons infected with human immunodeficiency virus type 1. Journal of Infectious Diseases 182, S69-S73.

Beare S \& Steward WP (1996) Plasma free iron and chemotherapy toxicity. Lancet 347, 342-343.

Beaton GH, Martorell R, Aronson KJ, Edmonston B, McCabe GP, Ross AC \& Harvey B (1993) Effectiveness of Vitamin A Supplementation in the Control of Young Child Morbidity and Mortality in Developing Countries. Geneva: World Health Organization.

Beattie JH \& Kwun I-S (2004) Is zinc deficiency a risk factor for atherosclerosis? British Journal of Nutrition 91, 177-181.

Beck MA (1999) Selenium and host defence towards viruses. Proceedings of the Nutrition Society 58, 707-711.

Beck MA, Kolbeck PC, Rohr LH, Shi Q, Morris VC \& Levander OA (1994) Vitamin E deficiency intensifies the myocardial injury of coxsackievirus B3 infection of mice. Journal of Nutrition 124, 345-358.

Beck MA \& Matthews CC (2000) Micronutrients and host resistance to viral infection. Proceedings of the Nutrition Society $\mathbf{5 9}$ 581-585.

Beisel WR (1976) Trace elements in infectious processes. Medical Clinics of North America 60, 831-849.

Beisel WR (1995) Infection-induced malnutrition: from cholera to cytokines. American Journal of Clinical Nutrition 62, 813-819.

Bengoa JM, Bolt MJ \& Rosenberg IH (1984) Hepatic vitamin D 25 -hydroxylase inhibition by cimetidine and isoniazid. Journal of Laboratory and Clinical Medicine 104, 546-552. 
Beresford CH, Neale RJ \& Brooks OG (1971) Iron absorption and pyrexia. Lancet i, 568-572.

Bland R, Zehnder D, Hughes SV, Ronco PM, Stewart PM \& Hewison M (2001) Regulation of vitamin D-1 $\alpha$-hydroxylase in a human cortical collecting duct cell line. Kidney International 60, 1277-1286.

Blomhoff R (1994) Vitamin A in Health and Disease. New York: Marcel Dekker.

Blot WJ, Li J-Y, Taylor PR, Guo W, Dawsay S, Wang G-Q, Yang CS, Zheng S-F, Gail M, Li G-Y, Yu Y, Liu B-Q, Tangrea J, Sun Y-H, Liu F, Fraumeni JF Jr, Zhang J-H \& Li B (1993) Nutrition intervention trials in Linxian, China: supplementation with specific vitamin/mineral combinations, cancer incidence, and disease specific mortality in the general population. Journal of the National Cancer Institute 85, 1483-1492.

Blumberg J \& Couris R (1999) Pharmacology, nutrition and the elderly: interactions and implications. In Geriatric Nutrition: The Health Professionals Handbook, pp. 342-365 [R Chernoff, editor]. Gaithersberg, MD: Aspen, Publishers Inc.

Bone RA, Landrum JT, Fernandez L \& Tarsis SL (1988) Analysis of the macular pigment by HPLC: retinal distribution and age study. Investigative Ophthalmology and Visual Science 29, 843-849.

Bourgeois CF (2003) Immune responses, reactive oxygen species and antioxidant vitamins. In Antioxidant Vitamins and Health. Cardiovascular Disease, Cancer, Cataracts and Aging, pp. 28-40 [CF Bourgeois, editor]. New York: HNB Publishing.

Braunschweig CL, Sowers M, Kovacevich DS, Hill GM \& August DA (1997) Parental zinc supplementation in adult humans during the acute phase response increases the febrile response. Journal of Nutrition 127, 70-74.

Bressler R (1993) Adverse drug reactions. In Geriatric Pharmacology, pp. 41-61 [R Bressler and MD Katz, editors]. New York: McGraw-Hill, Inc.

Briggs M \& Briggs M (1972) Vitamin C requirements and oral contraceptive. Nature 238, 277.

Brock J (1993) Iron and immunity. Journal of Nutritional Immunology 2, 47-106.

Brown KH, Peerson JM \& Allen LH (1998) Effect of zinc supplementation on children's growth: a meta-analysis of intervention trials. Bibliotheca Nutritio et Dieta (Basle) 54, 76-83.

Brune M, Rossander L \& Hallberg L (1989) Iron absorption and phenolic compounds: importance of different phenolic structures. European Journal of Clinical Nutrition 43, 546-557.

Brunette MG, Chan M, Ferriere C \& Roberts KD (2003) Site of $1,25(\mathrm{OH})_{2}$ vitamin $\mathrm{D}_{3}$ synthesis in the kidney. Nature 276, 287-289.

Bullen JJ (1981) The significance of iron in infection. Review of Infectious Diseases 3,1127-1138.

Burton GW \& Ingold KU (1984) $\beta$-Carotene: an unusual type of lipid antioxidant. Science 224, 569-573.

Cameron E \& Campbell A (1974) The orthomolecular treatment of cancer II. Clinical trial of high-dose ascorbic acid supplements in advanced human cancer. Chemico-Biological Interactions 9, 285-315.

Campbell GD Jr, Steinberg MH \& Bower JD (1975) Letter: Ascorbic acid induced haemolysis in G-6-PD deficiency. Annals of Internal Medicine 82, 810.

Campbell NR \& Hasinoff BB (1991) Iron supplements: a common cause of drug interactions. British Journal of Clinical Pharmacology 31, 251-255.

Campbell NR, Kara M, Hasinoff BB, Haddara WM \& McKay DW (1992) Norfloxacin interaction with antacids and minerals. British Journal of Clinical Pharmacology 33, 115-116.

Carreras MC, Pargament GA, Catz SD, Poderoso JJ \& Boveris A (1994) Kinetics of nitric oxide and hydrogen peroxide production and formation of peroxynitrite during the respiratory burst of human neutrophils. Federation of Experimental Biology and Science Letters 341, 65-68.

Cathcart AE \& Thurnham DI (1998) Thiamin: physiology. In Encyclopaedia of Human Nutrition, vol. 3, pp. 1858-1863 [MJ Sadler, B Caballero, and JJ Strain, editors]. London: Academic Press.

Chandra RK (1984) Excessive intake of zinc impairs immune response. Journal of the American Medical Association 252, 1443-1446.

Chaudiere J \& Ferrari-Iliou R (1999) Intracellular antioxidants from chemical to biochemical mechanisms. Food and Chemical Toxicology 37, 949-962.

Chevion M, Jiang Y, Har-El R, Berenshtein E, Uretzky G \& Kitrossky N (1993) Copper and iron are mobilised following myocardial ischemia: possible predictive criteria for tissue injury. Proceedings of the National Academy of Science USA 90, 1102-1106.

Christakos S, Raval-Pandya M, Wernyj RP \& Yang W (1996) Genomic mechanisms involved in the pleiotropic actions of 1,25-dihydroxyvitamin $\mathrm{D}_{3}$. Biochemical Journal 316, 361-371.

Christian P, Khatry SK, Katz J, Pradhan EK, LeClerq SC, Shrestha SR, Adhikari RK, Sommer A \& West KP Jr (2003) Effects of alternative maternal micronutrient supplements on low birth weight in rural Nepal: double-blind randomised community trial. British Medical Journal 326, 1-6.

Clavreul A, D'Hellencourt CL, Montero-Menei C, Potron G \& Couez D (1998) Vitamin D differentially regulates B7·1 and B7.2 expression on human peripheral blood monocytes. Immunology 95, 272-277.

Clohessy PA \& Golden BE (1996) Microbiostatic activity of human plasma and its relation to zinc and iron availability. Biochemical Society Transactions 24, 311S-312S.

Cogswell ME, Weisberg P \& Spong C (2003) Cigarette smoking, alcohol use and adverse pregnancy outcomes: implications for micronutrient supplementation. Journal of Nutrition 133, 1722S-1731S.

Conrad ME, Umbreit JN, Moore EG \& Parmley RT (1994) Hereditary hemochromatosis: a prevalent disorder of iron metabolism with an elusive etiology. American Journal of Hematology 47, 218-224.

Cotter AA \& Cashman KD (2003) Independent and combined effects of $17 \beta$-oestradiol and 1,25 dihyroxycholecalciferol on transepithelial calcium transport in Caco-2 cells maintained in an oestrogen-depleted environment. Proceedings of the Nutrition Society 62, 24A.

Cui L, Takagi Y, Wasa M, Liboshi Y, Khan J, Nezu R \& Okada A (1997) Induction of nitric oxide synthase in rat intestine by interleukin- $1 \alpha$ may explain diarrhea associated with zinc deficiency. Journal of Nutrition 127, 1729-1736.

Cui L, Takagi Y, Wasa M, Sando K, Khan J \& Okada A (1999) Nitric oxide synthase inhibitor attenuates intestinal damage induced by zinc deficiency in rats. Journal of Nutrition 129, 792-798.

Darvay A, Basarab T, McGregor JM \& Russell-Jones R (1999) Isoniazid induced pellagra despite pyridoxine supplementation. Clinical and Experimental Dermatology 24, 167-169.

Day AJ, Mellon F, Barron D, Sabrazin G, Morgan MRA \& Williamson G (2001) Human metabolism of dietary flavonoids: identification of plasma metabolites of quercetin. Free Radical Research 35, 941-952.

de la Fuente M, Ferrandez MD, Burgos MS, Soler A, Prieto A \& Miquel J (1998) Immune function in aged women is improved by ingestion of vitamins $\mathrm{C}$ and E. Canadian Journal of Physiology and Pharmacology 76, 373-380.

Delanghe JR, Langlois MR, Boelaert JR, Van Acker J, Van Wanzeele F, Van den Groen G, Hemmer R, Verhofstede C, De Buyzere M, De Banquer D, Arendt V \& Plum J (1998) 
Haptoglobin polymorphism, iron metabolism and mortality in HIV infection. AIDS 12, 1027.

Department of Health and Social Security (1979) Nutrition and Health in Old Age. Report on Health and Social Subjects no. 16. London: HM Stationery Office.

Diet and Health (1989) Implications for Reducing Chronic Disease. Washington, DC: National Academy Press.

Di Mascio P, Kaiser S \& Sies H (1989) Lycopene as the most efficient biological carotenoid singlet-oxygen quencher. Archives of Biochemistry and Biophysics 274, 532-538.

Disler P, Lynch SM, Charlton RW, Torrance JD, Walker R \& Mayet F (1975) The effect of tea on iron absorption. Gut 16, 193-200.

Dresser GK, Bailey DG \& Carruthers SG (2000) Grapefruit juice - felodipine interactions in the elderly. Clinical Pharmacology and Therapeutics $\mathbf{6 8}, 28-34$

Edgar JA (1970) Dehydroascorbic acid and cell division. Nature 227, 24-26.

Erickson KL, Medina EA \& Hubbard NE (2000) Micronutrients and innate immunity. Journal of Infectious Diseases 182, S5-S10.

Evans P \& Halliwell B (2001) Micronutrients: oxidant/antioxidant status. British Journal of Nutrition 85, Suppl. 2, S67-S74.

Evans RM, Currie L \& Campbell A (1982) The distribution of ascorbic acid between various cellular components of the blood in normal individuals, and its relation to the plasma concentration. British Journal of Nutrition 47, 473-482.

Fahmy M \& Young SP (1993) Modulation of iron metabolism in monocyte cell line U937 by inflammatory cytokines: changes in transferrin uptake, iron handling and ferritin mRNA. Biochemical Journal 296, 175-181.

Faruque O, Rahman Khan M, Rahman M \& Ahmed F (1995) Relationship between smoking and antioxidant status. British Journal of Nutrition 73, 625-632.

Fawzi WW, Msamanga G, Spiegelman D, Renjifo B, Bang H, Kapiga S, Coley J, Hertzmark E, Essex M \& Hunter DJ (2003) Transmission of HIV-1 through breastfeeding among women in Dar es Salaam, Tanzania. Journal of Acquired Immune Deficiency Syndromes 31, 331-338.

Feetam CL, Leach RH \& Meynell MJ (1975) Lack of clinically important interaction between warfarin and ascorbic acid. Toxicology and Applied Pharmacology 31, 544-547.

Fleck A \& Myers MA (1985) Diagnostic and prognostic significance of acute phase proteins. In The Acute Phase Response to Injury and Infection, pp. 249-271 [AH Gordon and A Koj, editors]. Amsterdam: Elsevier Scientific Publishers.

Foote CS \& Denny RW (1968) Chemistry of singlet oxygen. VII. Quenching by $\beta$-carotene. American Chemical Society Journal 90, 6233-6235.

Fraga CG, Motchnik PA, Shigenaga MK, Helbock HJ, Jacob RA \& Ames BN (1991) Ascorbic acid protects against endogenous oxidative DNA damage in human sperm. Proceedings of the National Academy of Science USA 88, 11003-11006.

Frei B (1991) Ascorbic acid protects lipids in human plasma and low-density lipoprotein against oxidative damage. American Journal of Clinical Nutrition 54, 1113S-1118S.

Friedman GJ, Sherry S \& Ralli EP (1941) The mechanism of the excretion of vitamin $\mathrm{C}$ by the human kidney at low and normal plasma levels of ascorbic acid. Journal of Clinical Investigation 20, 685-689.

Gallagher JC (2001) Role of estrogens in the management of postmenopausal bone loss. Rheumatic Diseases Clinics of North America 27, 143-162.

Galloway P, McMillan DC \& Sattar N (2000) Effect of the inflammatory response on trace element and vitamin status. Annals of Clinical Biochemistry 37, 289-297.

Gerster H (1991) Antioxidant protection of the ageing macula. Age and Ageing 20, 60-69.
Gianna M, Terao M, Gambacorti-Passerine C, Rabaldi A \& Garattine E (1996) Effects of 1,25-dihydroxyvitamin $D_{3}$ on alltrans retinoic acid sensitive and resistant acute promyelocytic leukemia cells. Biochemical and Biophysical Research Communications 224, 50-56.

Gokce N, Keaney JF, Frei B, Holbrook M, Olesiak M, Zachariah BJ, Leeuwenburgh C, Heinecke JW \& Vita JA (1999) Longterm ascorbic acid administration reverses endothelial vasomotor dysfunction in patients with coronary artery disease. Circulation 99, 3234-3240.

Goldman P (1997) Olestra: assessing its potential to interact with drugs in the gastrointestinal tract. Journal of Clinical Pharmacy and Therapeutics 61, 613-618.

Gordeuk V, Ballou S, Lozanski G \& Brittenham GM (1992) Decreased concentrations of tumor necrosis factor- $\alpha$ supernatants of monocytes from homozygotes for hereditary hemochromatosis. Blood 79, 1855-1860.

Grech ED, Dodd NJF, Jackson MJ, Morrison WL, Faragher EB \& Ramsdale DR (1996) Evidence of free-radical generation after primary percutaneous transluminal coronary angioplasty recanalization in acute myocardial infarction. American Journal of Cardiology 77, 122-127.

Green MH \& Green JB (1994) Dynamics and control of plasma retinol. In Vitamin A in Health \& Disease, pp. 119-133 [R Blomhoff, editor]. New York: Marcel Dekker Inc.

Greenberg ER, Baron JA, Stukel TA, Stevens MM, Mandel JS, Spencer SK, Elias PM, Lowe N, Nierenberg DW, Bayrd G, Corwin Vance J, Freeman DH Jr, Clendenning WE, Kwan T \& Skin Cancer Prevention Group (1990) A clinical trial of beta carotene to prevent basal-cell and squamous-cell cancers of the skin. New England Journal of Medicine 323, 789-795.

Greenman E, Phillipich MJ, Meyer CJ, Charamella LJ \& Dimitrov NV (1988) The effect of selenium on phagocytosis in humans. Anticancer Research 8, 825-828.

Guengerich FP (1995) Influence of nutrients and other dietary materials on cytochrome P450 enzymes. American Journal of Clinical Nutrition 61, 651S-658S

Guengerich FP, Martin MV, Beaune PH, Kremers P, Wolff T \& Waxman DJ (1986) Characterization of rat and human liver cytochrome $\mathrm{P} 450$ forms involved in nifedipine oxidation, a prototype for genetic polymorphism in oxidative drug metabolism. Journal of Biological Chemistry 261, 5051-5060.

Hahn TJ, Hendin BA, Sharp CR \& Haddad JG (1972) Effect of chronic anticonvulsant therapy on serum 25-hydroxycholecalciferol levels in adults. New England Journal of Medicine 287, 900.

Hallberg L \& Hulthen L (2004) Prediction of iron absorption: an algorithm for calculating absorption and bioavailability of dietary iron. American Journal of Clinical Nutrition $\mathbf{7 1}$, $1147-1160$

Halliwell B (1994) Vitamin C: the key to health or a slow-acting carcinogen? Redox Report 1, 5-9.

Halliwell B \& Gutteridge JMC (1985) Free Radicals in Biology and Medicine, 1 st ed. Oxford: Clarendon Press.

Halliwell B, Gutteridge JMC \& Cross CE (1992) Free radicals, antioxidants, and human disease: where are we now? Journal of Laboratory and Clinical Medicine 119, 598-620.

Hannah SS \& Norman AW (1994) 1 $\alpha, 25$-Dihyroxyvitamin $\mathrm{D}_{3}$ regulated expression of the eukaryotic genome. Nutrition Reviews 52, 376-382.

Harbourne J (1994) The Flavonoids: Advances in Research Since 1986. London: Chapman \& Hall.

Harris SS \& Dawson-Hughes B (1998) The association of oral contraceptive use with plasma 25-hydroxyvitamin D levels. Journal of the American College of Nutrition 17, 282-284.

Harvey PWJ, Heywood PF, Nesheim MC, Galme K, Zegans M, Habicht JP, Stephenson LS, Radimer KL, Brabin B, Forsyth K 
\& Alpers MP (1989) The effect of iron therapy on malaria infection in Papua New Guinean school children. American Journal of Tropical Medicine and Hygiene 40, 12-18.

Hathcock JN, Hattan DG, Jenkins MY, McDonald JT, Sundaresan PR \& Wilkening VL (1990) Evaluation of vitamin A toxicity. American Journal of Clinical Nutrition 52, 183-202.

Heinonen OP, Huttunen JK, Albanes D \& ATBC Cancer Prevention Study Group (1994) The effect of vitamin E and beta carotene on the incidence of lung cancer and other cancers in male smokers. New England Journal of Medicine 330, 1029-1035.

Hemila H, Roberts P \& Wikstrom M (1984) Activated polymorphonuclear leukocytes consume vitamin C. Federation of Experimental Biology and Science Letters 178, 25-30.

Hendriks HFJ, Westrate JA, Van Vliet T \& Meijer GW (1999) Spreads enriched with three different levels of vegetable oil sterols and the degree of cholesterol lowering in normocholesterolaemic and mildly hypercholesterolaemic subjects. European Journal of Clinical Nutrition 53, 319-327.

Hennekens CH, Buring JE, Manson JE, Stampfer M, Rosner B, Cook NR, Belanger C, LaMotte F, Gaziano JM, Ridker PM, Willett W \& Peto R (1996) Lack of effect of long-term supplementation with beta carotene on the incidence of malignant neoplasms and cardiovascular disease. New England Journal of Medicine 334, 1145-1149.

Herbaczynska-Cedro K, Klosiewicz-Wasek B, Cedro K, Wasek W, Panczenko-Kresowska B \& Wartanowicz M (1995) Supplementation with vitamin C and vitamin E suppresses leukocyte oxygen free radical production in patients with myocardial infarction. European Heart Journal 16, 1044-1049.

Herbaczynska-Cedro K, Wartanowicz M, Panczenko-Kresowska B, Cedro K, Klosiewicz-Wasek B \& Wasek W (1994) Inhibitory effect of vitamins $\mathrm{C}$ and $\mathrm{E}$ on the oxygen free radical production of human polymorphonuclear leucocytes. European Journal of Clinical Investigation 24, 316-319.

Hertog MGL, Feskens EJM, Hollman PCH, Katan MB \& Kromhout D (1993) Dietary antioxidant flavonoids and risk of coronary heart disease: the Zutphen Elderly Study. Lancet 342, 1007-1011.

Hesketh JE, Vasconcelos MH \& Bermano G (1998) Regulatory signals in messenger RNA: determinants of nutrient-gene interaction and metabolic compartmentation. British Journal of Nutrition 80, 307-321.

Hodkinson HM (1985) Screening for anaemia and its prevention. In Blood Disorders in the Elderly, pp. 100-108 [MJ Denham and I Chanarin, editors]. Edinburgh: Churchill Livingstone.

Hotz CS, Fitzpatrick DW, Trick KD \& Abbe MRL (1997) Dietary iodine and selenium interact to affect thyroid hormone metabolism of rats. Journal of Nutrition 127, 1214-1218.

Howie AF, Arthur JR, Nicol F, Walker SW, Beech SG \& Beckett GJ (1998) Identification of a 57-kilodalton selenoprotein in human thyrocytes as thioredoxin reductase and evidence that its expression is regulated through the calcium phosphoinositolsignalling pathway. Journal of Clinical Endocrinology and Metabolism 83, 2052-2058.

Hoyumpa AM \& Schenker S (1982) Major drug interactions: effect of liver disease, alcohol and malnutrition. Annual Review of Medicine 33, 113-149.

Hoyumpa AMJ, Nichols SG, Wilson FA \& Schenker S (1977) Effect of ethanol on intestinal $(\mathrm{Na}, \mathrm{K})$ ATPase and intestinal thiamin transport in rats. Journal of Laboratory and Clinical Medicine 90, 1086-1095.

Hulse JD, Ellis SR \& Henderson LM (1978) $\beta$-Hydroxylation of trimethyllysine by an $\alpha$-ketoglutarate-dependent mitochondrial dioxygenase. Journal of Biological Chemistry 253, 1654-1659.

Hume R \& Weyers E (1973) Changes in leucocyte ascorbic acid during the common cold. Scottish Medical Journal 18, 3-7.
Hussey GD \& Klein M (1990) A randomized, controlled trial of vitamin A in children with severe measles. New England Journal of Medicine 323, 160-164.

Hustad S, Ueland PM, Vollset SE, Zhang Y, Bjorke-Monsen AL \& Schneede J (2000) Riboflavin as a determinant of plasma total homocysteine: effect of modification by the methylenetetrahydrofolate reductase C677T polymorphism. Clinical Chemistry 46, 1065-1071.

Ibner FL, Blass JP \& Brin M (1982) Thiamin in the elderly, relation to alcoholism and to neurological degenerative disease. American Journal of Clinical Nutrition 36, 1067-1082.

Irvin TT, Chattopadhyay K \& Smythe A (1978) Ascorbic acid requirements in postoperative patients. Surgery, Gynecology and Obstetrics 147, 49-55.

Iwasaka K, Koyama M, Nogaki A, Maruyama S, Tamura A, Takano H, Takahama M, Kochi M, Satoh K \& Sakagami H (1998) Role of hydrogen peroxide in cytotoxicity induction by ascorbates and other redox compounds. Anticancer Research 18, 4333-4337.

Jacques PF, Selhub J, Bostom AG, Wilson PW \& Rosenberg IH (1995) Vitamin C intake, folate status, and plasma homocysteine in the Framingham study. www.nal.usda.gov/ttic/tektran/ data/000006/50/0000065046.html

Jayachandran M, Rani PJI, Arivazhagan P \& Panneerselvam C (2000) Neutrophil phagocytic function and humoral immune response with reference to ascorbate supplementation in aging humans. Journal of Anti-Aging Medicine 3, 37-42.

Jones DY, Miller KW, Koonsvitsky BP, Ebert ML, Lin PYT, Jones MB \& DeLuca HF (1991) Serum 25-hydroxyvitamin D concentrations of free-living subjects consuming olestra. American Journal of Clinical Nutrition 53, 1281-1287.

Kane GC \& Lipsky JJ (2000) Drug-grapefruit interactions. Mayo Clinic Proceedings 75, 933-942.

Karita K, Hamada GS \& Tsugani S (2001) Comparison of selenium status between Japanese living in Tokyo and Japanese Brazilians in Sao Paulo, Brazil. Asia-Pacific Journal of Public Health 10, 197-199.

Keen CL, Clegg MS, Hanna LA, Lanoue L, Rogers JM, Daston GP, Oteize P \& Uriu-Adams JY (2003) The plausibility of micronutrient deficiencies being a significant contributing factor to the occurrence of pregnancy complications. Journal of Nutrition 133, 1597S-1605S.

Keith ME \& Jeejeebhoy KN (1997) Immunonutrition. Bailliere's Clinical Endocrinology and Metabolism 11, 709-738.

Kejian Z \& Mrowietz U (1998) The effect of vitamin D and its analogues calcipotriol and tacalcitol on the differentiation of human monocyte-derived dendritic cells. Journal of Dermatological Science 16, 94.

Knowles J, Thurnham DI, Hill AVS, Tang C \& Greenwood BM (1991) Plasma ascorbate concentrations in human malaria. Proceedings of the Nutrition Society 50,66A.

Kopp EB \& Ghosh S (1995) NF-kB and rel proteins in innate immunity. Advances in Immunology 58, 1-27.

Koppenol WH, Moreno JJ, Pryor WA, Ischiropoulos H \& Beckman JS (1992) Peroxynitrite, a cloaked oxidant formed by nitric oxide and superoxide. Chemical Research in Toxicology 5, 834-842.

Kornbrust DJ \& Mavis RD (1979) Relative susceptibility of microsomes from lung, heart, liver, kidney, brain and testes to lipid peroxidation: correlation with vitamin E content. Lipids 15, 315-322.

Koskela TK, Reiss GR, Brubacher RF \& Ellefson RD (1989) Is the high concentrations of ascorbic acid in the eye an adaptation to intense solar irradiation? Investigative Ophthalmology and Visual Science 30, 2265-2267.

Kreutz M \& Andreesen R (1990) Induction of human monocyte to macrophage maturation in vitro by 1,25 -dihydroxyvitamin $D_{3}$. Blood 76, 2457-2461. 
Langlois MR \& Delanghe JR (1996) Biological and clinical significance of haptoglobin polymorphism in humans. Clinical Chemistry 42, 1589-1600.

Langlois MR, Delanghe JR, De Buyzere ML, Bernard DR \& Ouyang J (1997) Effect of haptoglobin on the metabolism of vitamin C. American Journal of Clinical Nutrition 66, 606-610.

Law MR \& Hackshaw AK (1997) A meta-analysis of cigarette smoking, bone mineral density and risk of hip fracture: recognition of a major effect. British Medical Journal 315, 841-846.

Lemire JM (1992) Immunomodulatory role of 1,25-dihydroxyvitamin $\mathrm{D}_{3}$. Journal of Cell Biochemistry 49, 26-31.

Lemire JM (1995) Immunomodulatory actions of 1,25-dihydroxyvitamin D3. Journal of Steroid Biochemistry and Molecular Biology 53, 599.

Leo MA \& Lieber CS (1982) Hepatic vitamin A depletion in alcoholic liver injury. New England Journal of Medicine 307, 597-601.

Leo MA \& Lieber CS (1999) Alcohol, vitamin A, and $\beta$-carotene: adverse interactions, including hepatotoxicity and carcinogenicity. American Journal of Clinical Nutrition 69, 1071-1085.

Lifschitz A, Virkel G, Mastromarino M \& Lanusse C (1997) Enhanced plasma availability of the metabolites of albendazole in fasted adult sheep. Veterinary Research Communications 21, 201-211.

Lips P (2003) Hypervitaminosis A and fractures. New England Journal of Medicine 348, 347-349.

Lockman PR, Shum S \& Allen DD (2001) Case report: visual toxicity in acute isoniazid overdose. International Journal of Medical Toxicology 4, 21-26.

Louw JA, Werbeck A, Louw ME, Kotze TJ, Cooper R \& Labadarios D (1992) Blood vitamin concentrations during the acute-phase response. Critical Care Medicine 20, 934-941.

Lubetsky A, Winaver J, Seligmann H, Olchovsky D, Almog S, Halkin H \& Ezra D (1999) Urinary thiamin excretion in the rat: effects of furosemide, other diuretics and volume load. Journal of Laboratory and Clinical Medicine 134, 232-237.

Lynch SR (1997) Interaction of iron with other nutrients. Nutrition Reviews 55, 102-110.

McCarver DG (2001) ADH2 and CYP2E1 genetic polymorphisms: risk factors for alcohol-related birth defects. Drug Metabolism and Disposition 29, 562-565.

McFarlane H, Reddy S, Adcock KJ, Adeshina H, Cooke AR \& Akene J (1970) Immunity, transferrin and survival in kwashiorkor. British Medical Journal 4, 268-270.

McKenzie RC, Rafferty SP \& Beckett GJ (1998) Selenium: an essential element for immune function. Trends in Immunology Today 19, 342-345.

Maehira F, Luyo GA, Miyagi I, Oshiro M, Yamane N, Kuba M \& Nakazato Y (2002) Alterations of serum selenium concentrations in the acute phase of pathological conditions. Clinica Chimica Acta 316, 137-146.

Maehira F, Miyagi I \& Eguchi Y (2003) Selenium regulates transcription factor NF- $\mathrm{KB}$ activation during the acute phase reaction. Clinica Chimica Acta 334, 163-171.

Mangelsdorf DJ (1994) Vitamin A receptors. Nutrition Reviews 52, S32-S44

Mantyla R, Mannisto PT, Vuorela A, Sundberg S \& Ottoila P (1984) Impairment of captopril bioavailability by concomitant food and antacid intake. International Journal of Clinical Pharmacology, Therapy and Toxicology 22, 626-629.

Marcus SL, Petrylak DP, Dutcher JP, Paietta E, Ciobanu N, Strauman J, Wiernik PH, Hutner SH, Frank O \& Baker H (1991) Hypovitaminosis C in patients treated with high-dose interleukin 2 and lymphokine-activated killer cells. American Journal of Clinical Nutrition 54, 1292S-1297S .

Mathews-Roth MM (1986) Systemic photoprotection. Dermatologic Clinics 4, 335-339.
Mehta JB, Singhal SB \& Mehta BC (1990) Ascorbic acid induced haemolysis in G-6-PD deficiency. Lancet 335, 944.

Miller RK, Hendrickx AG, Mills JL, Hummler H \& Wiegand UW (1998) Periconceptional vitamin A use: how much is teratogenic? International Journal of Vitamin and Nutrition Research 68, 411-416.

Mitchell SL \& Rockwood K (2001) The association between antiulcer medication and initiation of cobalamin replacement in older persons. Journal of Clinical Epidemiology 54, 531-534.

Miyaura C, Abe E, Kuribayashi T, Tanaka H, Konno K, Nishii Y \& Suda T (1981) 1 $\alpha, 25$-dihydroxyvitamin $\mathrm{D}_{3}$ induces differentiation of human myeloid leukemia cells. Biochemical and Biophysical Research Communications 102, 937-943.

Moncada S, Palmer RMJ \& Higgs EA (1991) Nitric oxide physiology, pathophysiology and pharmacology. Pharmacology Reviews 43, 109-142.

Morabia A, Bernstein MS \& Antonini S (2000) Smoking, dietary calcium and vitamin D deficiency in women: a populationbased study. European Journal Clinical Nutrition 54, 684-689.

Morrison NA, Ci JC, Tokita A, Kelly PJ, Crofts L, Nguyen TV, Sambrook KN \& Elsman JA (1994) Prediction of bone density from vitamin D receptor alleles. Nature 367, 284-287.

Moser U \& Weber F (1984) Uptake of ascorbic acid by human granulocytes. International Journal of Vitamin and Nutrition Research 54, 47-53.

Munoz C, Schlesinger L \& Carvaillon J-M (1995) Interaction between cytokines, nutrition and infection. Nutrition Research 15, 1815-1844.

Murphy ME (2002) Ascorbate and dehydroascorbate modulate nitric oxide-induced vasodilations of rat coronary arteries. Circulation 105, 1155-1157.

Myllyla R, Kuutti-Savolainen E-R \& Kivirikko KI (1978) The role of ascorbate in the prolyl hydroxylase reaction. Biochemical and Biophysical Research Communications 83, 441-448.

Nakamura K, Takahashi T, Sasaki Y, Tsuyoka R, Okuno Y, Kurino M, Ohmori K, Iho S \& Nakao K (1996) 1,25-Dihydroxyvitamin D3 differentiates normal neutrophilic promyelocytes to monocytes/macrophages in vitro. Blood 87, 2693-2701.

Nelder KH \& Hambidge KM (1975) Zinc therapy in acrodermatitis enteropathica. New England Journal of Medicine 292, 879-882.

Nelson DR (1999) Cytochrome P450 and the individuality of species. Archives of Biochemistry and Biophysics 369, 1-10.

Nelson DR (2003) Cytochrome P450s in humans. http:// drnelson.utmem.edu/P450lect.html

Niki E, Tsuchiya J, Tanimura R \& Kamiya Y (1982) Regeneration of vitamin $\mathrm{E}$ from $\alpha$-chromanoxyl radical by glutathione and vitamin C. Chemistry Letters 27, 789-792.

Olszak IT, Poznansky MC, Evans RH, Olson D, Kos C, Pollak MR, Brown EM \& Scadden DT (2000) Extracellular calcium elicits a chemokinetic response from monocytes in vitro and in vivo. Journal of Clinical Investigation 105, 1299-1305.

Omenn GS, Goodman GE, Thornquist MD, Balmes J, Cullen MR, Glass A, Keogh JP, Meyskens FL Jr, Valanis B, Williams JH Jr, Barnhart S \& Hammer S (1996) Effects of a combination of beta carotene and vitamin A on lung cancer and cardiovascular disease. New England Journal of Medicine 334, 1150-1155.

Oppenheimer SJ (1989) Iron and malaria. Parasitology Today 5, 77-79.

Oppenheimer SJ, Gibson FD, MacFarlane SBJ, Moody JB, Harrison C, Spencer A \& Bunari O (1986) Iron supplementation increases prevalence and effects of malaria: report on clinical studies in Papua New Guinea. Transactions of the Royal Society of Tropical Medicine and Hygiene 80, 603-612.

Osendarp SJM, West CE, Black RE \& Maternal Zinc Supplementation Study Group (2003) The need for maternal 
zinc supplementation in developing countries: an unresolved issue. Journal of Nutrition 133, 817S-827S.

Packer JE, Slater TF \& Willson RL (1979) Direct observations of a free radical interaction between vitamin $\mathrm{E}$ and vitamin $\mathrm{C}$. Nature 278, 737-738.

Palozza P (1998) Prooxidant actions of carotenoids in biologic systems. Nutrition Reviews 56, 257-265.

Palozza P \& Krinsky NI (1992) $\beta$-Carotene and $\alpha$-tocopherol are synergistic antioxidants. Archives of Biochemistry and Biophysics 297, 184-187.

Pantopoulos K, Weiss G \& Hentze MW (1994) Nitric oxide and the post-transcriptional control of cellular iron traffic. Trends in Cell Biology 4, 82-86.

Paolini M, Cantelli-Forti G, Perocco P, Pedulli GF, Abel-Rahman SZ \& Legator MS (1999) Co-carcinogenic effect of $\beta$-carotene. Nature 398, 760-761.

Pattison SE, Telles S, Friar S, Stowell C \& Beckley R (2004) Zinc diffusion through lipid bilayers. Archives of Biochemistry and Biophysics 351, 41-46.

Pekarek RS, Burghen GA, Bartelloni PJ, Calia FM, Bostian KA \& Beisel WR (1969) The effect of live attenuated Venezuelan equine encephalomyelitis virus vaccine on serum iron, zinc, and copper concentrations in man. Journal of Laboratory and Clinical Medicine 76, 293-303.

Pelkonen O, Rautio A, Raunio H \& Pasanen M (2000) CYP2A6: a human coumarin 7-hydroxylase. Toxicology 144, 139-147.

Pennypacker LC, Allen RH, Kelly JP, Matthews LM, Grigsby J, Kaye K, Lindenbaum J \& Stabler SP (1991) High prevalence of cobalamin deficiency in elderly outpatients. Journal of the American Geriatrics Society 39, 1155-1159.

Pepersack T, Garbusinski J, Robberecht J, Beyer I, Willems D \& Fuss M (1999) Clinical relevance of thiamine status amongst hospitalised elderly patients. Gerontology 45, 96-101.

Pharmaceutical Information (2004) Fansidar. http://www. rocheusa.com/products/fansidar/pi.pdf

Pokorny J, Yanishlieva N \& Gordon M (2001) Antioxidants in Food - Practical Applications. Cambridge, UK: Woodhead Publishing Ltd.

Polk RE, Healy DP, Sahai J, Drwal L \& Racht E (1989) Effect of ferrous sulfate and multivitamins with zinc on absorption of ciprofloxacin in normal volunteers. Antimicrobial Agents and Chemotherapeutics 33, 1841-1844.

Powers HJ (1987) The potential of a ${ }^{13} \mathrm{C}$-Methacetin breath test for estimating ascorbic acid requirements. International Journal of Vitamin and Nutrition Research 57, 455.

Powers HJ (1991) The use of stable isotopes in vitamin research. In New Techniques in Nutritional Research, pp. 95-111 [RG Whitehead and A Prentice, editors]. New York: Academic Press.

Prasad AS (1998) Zinc and immunity. Molecular and Cell Biochemistry 188, 63-69.

Prasad AS, Beck FJ, Grabowski SM, Kaplan J \& Mathog RH (1997) Zinc deficiency changes in cytokine production and Tcell subpopulations in patients with head and neck cancer and non-cancer subjects. Proceedings of the Association of American Physicians 109, 68-77.

Provvedini DM, Tsoukas CD, Deftos LJ \& Manolagas SC (1983) 1,25-Dihydroxyvitamin $\mathrm{D}_{3}$ receptors in human leukocytes. Science 221, 1181-1183.

Ramanathan R, Das NP \& Tan CH (1994) Effects of gammalinolenic acid, flavonoids, and other vitamins on cytotoxicity and lipid peroxidation. Free Radical Biology and Medicine 16, 43-48.

Rapuri PB, Gallagher JC, Balhorn KE \& Ryschon KL (2000) Smoking and bone metabolism in elderly women. Bone 27, 429-436.

Raunio H, Rautio A, Gullsten H \& Pelkonen O (2001) Polymorphisms of CYP2A6 and its practical consequences. British Journal of Clinical Pharmacology 52, 357-363.
Reddy MB, Hurrell RF \& Cook J (2000) Estimation of nonhemeiron bioavailability from meal composition. American Journal of Clinical Nutrition 71, 937-943.

Reddy V, Bhaskaram P, Raghuramulu N, Milton RC, Rao V, Madhusudan J \& Radha Krishna KV (1986) Relationship between measles, malnutrition, and blindness: a prospective study in Indian children. American Journal of Clinical Nutrition 44, 924-930.

Reibnegger G, Fuchs D \& Hausen A (1987) The dependence of cell-mediated immune activation in malaria on age and endemicity. Transactions of the Royal Society of Tropical Medicine and Hygiene 81, 729-733.

Rieck J, Halkin H, Almog S, Seligman H, Lubetsky A, Olchovsky D \& Ezra D (1999) Urinary loss of thiamin is increased by low doses of furosemide in healthy volunteers. Journal of Laboratory and Clinical Medicine 134, 238-243.

Riemersma RA, Carruthers KF, Elton RA \& Fox K (2000) Vitamin $\mathrm{C}$ and the risk of acute myocardial infarction. American Journal of Clinical Nutrition 71, 1181-1186.

Rink L \& Gabriel P (2000) Zinc and the immune system. Proceedings of the Nutrition Society 59, 541-552.

Rock CL, Thornquist MD, Kristal AR, Patterson RE, Cooper DA, Neuhouser ML, Neumark-Sztainer D \& Cheskin LJ (1999) Demographic, dietary and lifestyle factors differentially explain variability in serum carotenoids and fat-soluble vitamins: baseline results from the sentinel site of the Olestra post-marketing surveillance study. Journal of Nutrition 129, 855-864.

Roe DA (1985) Prediction of the cause, effects and prevention of drug-nutrient interactions. Drug-Nutrient Interactions $\mathbf{3}$, 187-189.

Roe DA (1993) Drug and food interactions as they affect the nutrition of older individuals. Aging (Milano) 5, Suppl. 1, 51-53.

Romero JA \& Kuczler FJ Jr (1998) Isoniazid overdose: recognition and management. American Family Physician 57, 749-752.

Roomi MW, House D, Eckert-Maksic M, Maksic ZB \& Tsao CS (1998) Growth suppression of malignant leukemia cell line in vitro by ascorbic acid (vitamin C) and its derivatives. Cancer Letters 122, 93-99.

Root-Bernstein R, Busik JV \& Henry DN (2002) Are diabetic neuropathy, retinopathy and neuropathy caused by hyperglycemic exclusion of dehydroascorbate uptake by glucose transporters. Journal of Theoretical Biology 216, 345-359.

Rosales FJ, Ritter SJ, Zolfaghari R, Smith JE \& Ross AC (1996) Effects of acute inflammation on plasma retinol, retinol-binding protein, and its messenger RNA in the liver and kidneys of vitamin A sufficient rats. Journal of Lipid Research 37, 962-971.

Ross AC (1996) Vitamin A deficiency and retinoid repletion regulate the antibody response to bacterial antigens and the maintenance of natural killer cells. Clinical Immunology and Immunopathology 80, S63-S72.

Ross AC (1998) Vitamin A supplementation as therapy - are the benefits disease specific. American Journal of Clinical Nutrition 68, 8-9.

Ross AC \& Hammerling UG (1994) Retinoids and the immune system. In The Retinoids: Biology, Chemistry and Medicine, 2nd ed., pp. 521-543 [MB Sporn, AB Roberts and DS Goodman, editors]. New York: Raven Press.

Rowe PM (1996) Beta-carotene takes a collective beating. Lancet 347, 249.

Russell RM (2000) The vitamin A spectrum: from deficiency to toxicity. American Journal of Clinical Nutrition 71, 884.

Sahud MA \& Cohen RJ (1971) Effect of aspirin ingestion on ascorbic acid levels in rheumatoid arthritis. Lancet i, 937-938.

Sandstrom B (2001) Micronutrient interactions: effects on absorption and bioavailability. British Journal of Nutrition 85, S181S185.

Sargeant LA, Luben RN, Wareham NJ, Oakes S, Bingham SA, 
Welch A, Day NE \& Khaw KT (2000) Vitamin C and hyperglycaemia in the European Prospective Investigation into Cancer Norfolk (EPIC-Norfolk) study. Diabetes Care 23, 726-732.

Schaefer JP, Tam Y, Hasinoff BB, Tawfik S, Peng Y, Reimche L \& Campbell NR (1998) Ferrous sulphate interacts with captopril. British Journal of Clinical Pharmacology 46, 377-381.

Schafer H, Naber K \& Adam D (1989) Haemostasestorungen bei Cephalosporinen mit einer $N$-Methyl-thiotetrazol-Seitenkette; Eine randomisierte Pilotstudie (Haemostasis disturbance caused by cephalosporins with an $N$-methylthiotetrazole side chain). Arznimettelforschung 39, 1156-1162.

Schlesinger L, Arevalo M, Arredondo S, Lonnerdal B \& Stekel A (1993) Zinc supplementation impairs monocyte function. Acta Paediatrica 82, 734-738.

Schreck R, Meier B, Mannel D, Droge W \& Baeuerle PA (1992) Dithiocarbamates as potent inhibitors of nuclear factor kappa B activation in intact cells. Journal of Experimental Medicine 175, 1181-1194.

Schreck R, Reiber P \& Baeuerle PA (1991) Reactive oxygen intermediates as apparently widely used messengers in the activation of NF-kB transcription factor and HIV-1. The EMBO Journal 10, 2247-2258.

Selhub J (1999) Homocysteine metabolism. Annual Review of Nutrition 19, 217-246.

Selhub J, Seyoum E, Pomfret AE \& Zeisel SH (1991) Effects of choline deficiency and methotrexate treatment upon liver folate content and distribution. Cancer Research 51, 16-21.

Shibaki A, Hosokawa K, Kawashima T, Koizumi H, Kobayashi H \& Ohkawara A (1998) Inhibitory effect of vitamin D and retinoids on human monocyte cytokine production. Journal of Dermatological Science 16, 188.

Sierksma A, Westrate JA \& Meijer GW (1999) Spreads enriched with plant sterols, either esterified 4,4-dimethylsterols or free 4desmethylsterols, and plasma total- and LDL-cholesterol. British Journal of Nutrition 82, 273-282.

Sipe JD (1985) Cellular and humoral components of the early inflammatory reaction. In The Acute Phase Response to Injury and Infection, 1st ed., pp. 3-21 [AH Gordon and A Koj, editors]. London: Elsevier.

Smith CH \& Bidlack WR (1984) Dietary concerns associated with the use of medications. Journal of the American Dietetic Association 84, 901-914.

Smith TJ \& Yang CS (1994) Effect of food phytochemicals on xenobiotic metabolism and tumorigenesis. In Food Phytochemicals for Cancer Prevention, pp. 17-48 [M-T Huang, T Osawa, C-T Ho and RT Rosen, editors]. Washington, DC: American Chemical Society.

Spittler A, Willheim M, Leutmezer F, Ohler R, Krugluger W, Reissner C, Lucas T, Brodowicz T, Roth E \& Boltz-Nitulescu G (1997) Effects of 1 $\alpha, 25$-dihydroxyvitamin D3 and cytokines on the expression of MHC antigens, complement receptors and other antigens on human blood monocytes and U937 cells: role in cell differentiation, activation and phagocytosis. Immunology 90, 286-293.

Steel DM \& Whitehead AS (1994) The major acute phase reactants: C-reactive protein, serum amyloid $\mathrm{P}$ component and serum amyloid A protein. Immunology Today 15, 81-88.

Stenton SB, Bungard TJ \& Ackman ML (2001) Interactions between Warfarin and herbal products, minerals and vitamins: a pharmacist's guide. Canadian Journal of Hospital Pharmacists 54, 186-192.

Stephensen CB, Franchi LM, Hernandez H, Campos M, Colarossi A \& Gilman RH (2002a) Assessment of vitamin A status with the relative dose response test in Peruvian children recovering from pneumonia. American Journal of Clinical Nutrition 76, $1351-1357$.
Stephensen CB, Rasooly R, Jiang X, Ceddia MA, Weaver CT, Chandraratna RAS \& Patterson Bucy R (2002b) Vitamin A enhances in vitro $\mathrm{Th} 2$ development via retinoid $\mathrm{X}$ receptor pathway. Journal of Immunology 168, 4495-4503.

Stieger R, Baumgartner K \& Heff U (1992) Gefaehrliche hypoprothrombinaemische Blutungen unter Antibiotikatherapie (Dangerous hypoprothrombinaemic haemorrhage in antibiotic therapy). Helvetica Chirurgica Acta 58, 775-778.

Stoltzfus RJ (1997) Rethinking anaemia surveillance. Lancet 349, 1764-1766.

Suter PM \& Vetter W (2000) Diuretics and vitamin B1: are diuretics a risk factor for thiamin malnutrition. Nutrition Reviews $\mathbf{5 8}$, 319-323.

Temme EHM \& van Hoydonck PGA (2002) Tea consumption and iron status. European Journal of Clinical Nutrition 56, 379-386.

Temmerman W, Dhondt A \& Vandewoude K (1999) Acute isoniazid intoxication: seizures, acidosis and coma. Acta Clinica Belgique 54, 211-216.

Terao J, Yamaguchi S, Shirai M, Miyoshi M, Moon J-H, Oshima S, Inakuma T, Tsushida T \& Kato Y (2001) Protection by quercetin and quercetin 3-O- $\beta$-D-glucuronide of peroxynitriteinduced antioxidant consumption in human plasma low-density lipoprotein. Free Radical Research 35, 925-931.

Testa U, Masciulli R, Tritarelli E, Pustorino R, Mariani G, Martucci R, Barberi T, Camagna A, Valtieri M \& Peschle C (1993) Transforming growth factor- $\beta$ potentiates vitamin D3induced terminal monocytic differentiation of human leukemic cell lines. Journal of Immunology 150, 2418-2430.

Thomas JA (1995) Drug-nutrient interactions. Nutrition Reviews 53, 271-282.

Thomas JA \& Burns RA (1998) Important drug-nutrient interactions in the elderly. Drugs and Aging 13, 199-209.

Thompson D, Milford-Ward A \& Whicher JT (1992) The value of acute phase protein measurements in clinical practice. Annals of Clinical Biochemistry 29, 123-131.

Thomson AD, Baker H \& Leevy CM (1970) Thiamine absorption in alcoholism. American Journal of Clinical Nutrition 21 , 537-538.

Thurnham DI (1990a) Anti-oxidant vitamins and cancer prevention. Journal of Micronutrient Analysis 7, 279-299.

Thurnham DI (1990b) Antioxidants and prooxidants in malnourished populations. Proceedings of the Nutrition Society $\mathbf{4 8}$ 247-259.

Thurnham DI (1994a) Carotenoids: functions and fallacies. Proceedings of the Nutrition Society 53, 77-87.

Thurnham DI (1994b) $\beta$-Carotene, are we misreading the signals in risk groups? Some analogies with vitamin C. Proceedings of the Nutrition Society 53, 557-569.

Thurnham DI (1995) Iron as a pro-oxidant. In Iron, Nutritional and Physiological Significance, pp. 31-41 [BA Wharton and M Ashwell, editors]. London: Chapman \& Hall.

Thurnham DI (1997a) Impact of disease on markers of micronutrient status. Proceedings of the Nutrition Society 56, 421-431.

Thurnham DI (1997b) Micronutrients and immune function: some recent developments. Journal of Clinical Pathology 50, 887-891.

Thurnham DI, Munoz N, Lu J-B, Wahrendorf J, Zheng S-F, Hambidge KM \& Crespi M (1988) Nutritional and haematological status of Chinese farms: the influence of 13.5 months treatment with riboflavin, retinol and zinc. European Journal of Clinical Nutrition 42, 647-660.

Thurnham DI \& Northrop-Clewes CA (2003) Effects of infection on nutritional and immune status. In Diet and Human Immune Function, pp.35-64 [DA Hughes, LG Darlington and A Bendich, editors]. Totowa, NJ: Humana Press. 
Thurnham DI \& Singkamani R (1991) The acute phase response and vitamin A status in malaria. Transactions of the Royal Society of Tropical Medicine and Hygiene 85, 194-199.

Tilg H, Dinarello CA \& Mier JW (1997) IL-6 and APPs: antiinflammatory and immunosuppressive mediators. Immunology Today 18, 428-432.

Tran TN, Eubanks SK, Shaffer KJ, Zhou CYJ \& Linder MC (1997) Secretion of ferritin by rat hepatoma cells and its regulation by inflammatory cytokines and iron. Blood 90, 4979-4986.

Tsuchiya M, Asada A, Kasahara E, Sato EF, Shindo M \& Inoue M (2002) Smoking a single cigarette rapidly reduces combined concentrations of nitrate and nitrite and concentrations of antioxidants in plasma. Circulation 105, 1155-1157.

Underwood BA (2003) Scientific research: essential, but is it enough to combat world food insecurities. Journal of Nutrition 133, 1434S-1437S.

Underwood BA \& Arthur JR (1996) The contribution of vitamin A to public health. Journal of the Federations of American Societies of Experimental Biology 10, 1040-1048.

Vallance P, Hume R \& Weyers E (1978) Reassessment of changes in leucocyte and serum ascorbic acid after acute myocardial infarction. British Heart Journal 40, 684-689.

Vallance S (1986) Platelets, leucocytes and buffy layer vitamin C after surgery. Human Nutrition. Clinical Nutrition 40C, 35-41.

van Kraaij DJ, Jansen RW, de Gier JJ, Gribnau FW \& Hoefnagels WH (1998) Prescription patterns of diuretics in Dutch community-dwelling elderly patients. British Journal of Clinical Pharmacology 46, 403-407.

Varela-Moreiras G, Ragel G \& Ruiz-Roso B (1993) Effects of prolonged aspirin or acetaminophen administration to rats on liver folate content and distribution. Relation to DNA methylation and S-adenosylmethione. International Journal of Vitamin and Nutrition Research 63, 41-46.

Walter T, Olivares M, Pizarro F \& Munoz C (1997) Iron, anemia and infection. Nutrition Reviews 55, 111-124.

Wang Y, Mackenzie B, Tsukaguchi H, Weremowicz S, Morton CC \& Hediger MA (2000) Human vitamin C (L-ascorbic acid) transporter SVCT1. Biochemical and Biophysical Research Communications 267, 488-494.

Wang Y, Russo TA, Kwon O, Chanock S, Rumsey SC \& Levine M (1997) Ascorbate recycling in human neutrophils: induction by bacteria. Proceedings of the National Academy of Science USA 94, 13816-13819.

Ward M (2001) Homocysteine, folate and cardiovascular disease. International Journal of Vitamin and Nutrition Research 71, 173-178.

Washko PW, Wang Y \& Levine M (1993) Ascorbic acid recycling in human neutrophils. Journal of Biological Chemistry 268, 15531-15535.

Wefers H \& Sies H (1988) The protection by ascorbate and glutathione against microsomal lipid peroxidation is dependent on vitamin E. European Journal of Biochemistry 174, 353-357.

Wegner C \& Nau H (1992) Alteration in embryonic folate metabolism by valproic acid during organogenesis: implications for the mechanisms of teratogenesis. Neurology 42, 17-24.

Weinberg ED (1984) Iron withholding: a defense against infection and neoplasia. Physiological Reviews 64, 65-102.

Weiss G, Goosen B, Doppler W, Fuchs D, Pantopoulos K, WernerFelmayer G, Wachter H \& Hentze MW (1993) Translation regu- lation via iron-responsive elements by the nitric oxide/ NO-synthase pathway. The EMBO Journal 12,3651-3657.

Weiss G, Wachter H \& Fuchs D (1995) Linkage of cell-mediated immunity to iron metabolism. Immunology Today 16, 495-500.

Wellinghausen N, Kirchner H \& Rink L (1997) The immunobiology of zinc. Immunology Today 18, 519-521.

Wiegand UW, Hartmann S \& Hummler H (1998) Safety of vitamin A: recent results. International Journal for Vitamin and Nutrition Research 68, 411-416.

Wilkinson IB, Megson IL, MacCallum H, Sogo N, Cockroft JR \& Webb DJ (1999) Oral vitamin C reduces arterial stiffness and platelet aggregation in human. Cardiovascular Pharmacology 34, 693.

Will JC, Ford ES \& Bowman BA (1999) Serum vitamin C concentrations and diabetes: findings from the third National Health and Nutrition Examination Survey, 1988-1994. American Journal of Clinical Nutrition 70, 49-52.

Windsor ACM, Hobbs CB, Treby DA \& Astley Cowper R (1972) Effect of tetracycline on leucocyte ascorbic acid levels. British Medical Journal 1, 214-215.

Wood JD \& Peesker SJ (1972) The effect on GABA metabolism in brain of isonicotinic acid hydrazide and pyridoxine as a function of time after administration. Journal of Neurochemistry $\mathbf{1 9}$, $1527-1537$.

World Health Organization (1990) Diet, Nutrition and the Prevention of Chronic Diseases. Geneva: WHO.

Wu X, Itoh N, Taniguchi T, Nakanishi T, Tatsu Y, Yumoko N \& Tanaka K (2003) Zinc-induced sodium-dependent vitamin C transporter 2 expression: potent roles in osteoblast differentiation. Archives of Biochemistry and Biophysics 420, 114-120.

Wudarczyk J, Debska G \& Lenartowicz E (1999) Zinc as an inducer of the membrane permeability transition in rat liver mitochondria. Archives of Biochemistry and Biophysics 363, 1-8.

Yang CS, Smith TJ \& Hong J-Y (1994) Cytochrome P-450 enzymes as targets for chemoprevention against chemical carcinogenesis and toxicity: opportunities and limitations. Cancer Research 54, S1982-S1986.

Yu VC, Delsert C, Andersen B, Holloway JM, Davary OV, Naar AM, Kim SY, Boutin J-M, Glass CK \& Rosenfeld MG (1991) RXRß: a coregulator that enhances binding of retinoic acid, thyroid hormone and vitamin $\mathrm{D}$ receptors to their cognate response elements. Cell 67, 1251-1266.

Zangen A, Botzer D, Zangen R \& Shainberg A (1998) Furosemide and digoxin inhibit thiamine uptake in cardiac cells. European Journal of Pharmacology 361, 151-155.

Zannoni VG \& Lynch MM (1973) The role of ascorbic acid in drug metabolism. Drug Metabolism Reviews 2, 57-69.

Zimmermann MB, Adou P, Torresani T, Zeder C \& Hurrell RF (2003) Effect of oral iodized oil on thyroid size and thyroid hormone metabolism in children with concurrent selenium and iodine deficiency. European Journal of Clinical Nutrition 54, 209-213.

Zinc Investigators Collaborative Group (1999) Prevention of diarrhea and pneumonia by zinc supplementation in children in developing countries: pooled analysis of randomized controlled trials. Journal of Pediatrics 135, 689-697.

Zinc Investigators Collaborative Group (2000) Therapeutic effects of oral zinc in acute and persistent diarrhea in children in developing countries: pooled analysis of randomized controlled trials. American Journal of Clinical Nutrition 72, 1516-1522. 